\title{
Ubiquitin pathways in neurodegenerative disease
}

\section{Graham Atkin * and Henry Paulson}

Department of Neurology, University of Michigan, Ann Arbor, MI, USA

\section{Edited by:}

Fred Van Leeuwen, Maastricht

University, Netherlands

\section{Reviewed by:}

Hansen Wang, University of

Toronto, Canada

Baojin Ding, University of

Massachusetts Medical School, USA

*Correspondence:

Graham Atkin, Department of Neurology, University of Michigan,

Rm. 4160, Biomedical Science

Research Building, 109 Zina Pitcher

Place, Ann Arbor, MI 48104, USA

e-mail: atking@umich.edu
Control of proper protein synthesis, function, and turnover is essential for the health of all cells. In neurons these demands take on the additional importance of supporting and regulating the highly dynamic connections between neurons that are necessary for cognitive function, learning, and memory. Regulating multiple unique synaptic protein environments within a single neuron while maintaining cell health requires the highly regulated processes of ubiquitination and degradation of ubiquitinated proteins through the proteasome. In this review, we examine the effects of dysregulated ubiquitination and protein clearance on the handling of disease-associated proteins and neuronal health in the most common neurodegenerative diseases.

Keywords: ubiquitin, neurodegenerative diseases, proteasome, protein quality control, Alzheimer's disease, Parkinson disease, Amyotrophic Lateral Sclerosis, Huntington's disease

\section{INTRODUCTION}

The unique demands placed on neurons by their exquisitely complicated and dynamic architecture have been appreciated by investigators for over 100 years (Golgi, 1886; Ramon y Cajal, 1909; Herculano-Houzel, 2011). A recent study places the number of neurons in the human brain at approximately 85 billion (Azevedo et al., 2009). With each neuron making upwards of 10 thousand synaptic connections, the estimated total number of synapses reaches toward 8.5 hundred trillion $\left(8.5 \times 10^{14}\right)$. Astonishingly, plasticity can occur selectively at particular subsets of synapses within a neuron, even down to the level of a single specified synapse (Lee et al., 2010). Failure to maintain these synaptic connections and their proper plasticity are hallmarks of a host of neurodegenerative diseases, and loss of synaptic connections correlates with diminished cognitive function even before neurons degenerate (Masliah et al., 1991a,b). With 2788 unique proteins already identified as integral to the composition of each synapse (Pielot et al., 2012), the management of unique protein environments requires sufficiently complex and modifiable systems of protein quality control. The Ubiquitin Proteasome System (UPS), a set of interacting enzymes and associated proteins, is able to address these diverse proteostatic needs through the orchestrated activity of over 500 components working in versatile combinations to regulate protein-protein interactions and eliminate unwanted proteins. As newly synthesized proteins form new structures and connections, the UPS works to ensure that old proteins are degraded to make way and that the proper complement of building materials is available. To achieve these functions, components of the UPS are recruited to dendritic spines in response to synaptic activity (Bingol and Schuman, 2006; Bingol et al., 2010). Evidence continues to mount for the necessity of UPS involvement in the dynamic remodeling of synaptic structures following synaptic activity (Hegde et al., 1997; Ehlers, 2003; Pak and Sheng, 2003; Patrick et al., 2003; Bingol and Schuman, 2004; Hung et al., 2010; Fu et al., 2011). Many synaptic components have been identified as activity-dependent substrates for agents of the UPS. These include postsynaptic receptors (Kato et al., 2005; Lussier et al., 2011) and the scaffolding proteins which hold them in place (Colledge et al., 2003; Shin et al., 2012). Transsynaptic proteins such as Beta-Catenin and Beta-Integrin align and connect pre- and post-synaptic elements and are degraded through the UPS (Yoshida et al., 2002; Dreier et al., 2005). The shape, size, and placement of dendritic spines are also determined in part by proteins that regulate cytoskeletal organization and are themselves subject to ubiquitin-mediated degradation (Bingol and Schuman, 2005; Marland et al., 2011). These contributions to synapse maintenance and synaptic plasticity require that the UPS functions properly. For example, pharmacologic inhibition of the UPS leads to a frank reduction in activity-dependent synaptic plasticity (Ehlers, 2003) and a dose-dependent loss of synaptic connections (Bajic et al., 2012). Robust loss of synaptic connections is evident in all of the major neurodegenerative disorders. The full role of ubiquitination pertaining to synaptic structure and function remains incompletely understood, but has been the focus of significant investigation (Hegde and Upadhya, 2007; Bingol and Sheng, 2011; Hanus and Schuman, 2013).

As important as the contributions of the UPS to maintaining the plasticity of synapses are its diverse roles in ensuring general cell health, including the elimination of misfolded or damaged proteins, mediation of receptor signaling pathways, response to DNA damage and oxidative stress, and progression of the cell cycle, among other roles (Bernassola et al., 2010; Shang and Taylor, 2011). UPS function is essential to cell health and survival in all cell types. Improper clearance of proteins is believed to be a causative or contributing factor in many neurodegenerative diseases, which are often characterized by the accumulation of aggregated proteins (Alves-Rodrigues et al., 1998; Huang and Figueiredo-Pereira, 2010). Whether aggregation itself is the cause of toxicity or merely represents a strategy by which neurons sequester toxic proteins remains contested (Ross and Poirier, 
2005), but the failure of quality control pathways to eliminate these unwanted proteins is evident. UPS dysfunction has been reported in the most common neurodegenerative diseases, including Alzheimer's disease (AD), Parkinson's disease (PD), Amyotrophic Lateral Sclerosis (ALS), and Huntington's disease (HD), as well as less common disorders and various animal models of protein aggregation (Keller et al., 2000; Bence et al., 2001; McNaught et al., 2003; Seo et al., 2004; Lonskaya et al., 2013). How the UPS becomes impaired in disease states is not always clear, as too little is known about how disease-related proteins are handled under normal conditions. Research into these areas has begun to reveal just how intricate and extensive ubiquitinmediated processes within the cell are, and accordingly, just how significant their dysregulation in a pathogenic context must be. Recent studies describing the plurality of ubiquitin-related abnormalities seen in disease states suggest the intriguing possibility that the disruption of one such process leads into that of another. Hopefully, further investigations will uncover potential therapeutic interventions.

\section{UBIQUITINATION AND THE UBIQUITIN PROTEASOME SYSTEM}

Ubiquitin is a 76 amino acid $(\sim 8 \mathrm{kDa})$ protein expressed in all eukaryotic cells. It is highly conserved throughout evolution; the amino acid sequence of human ubiquitin is identical to that of Aplysia (Hegde et al., 2000) and nearly identical to that of yeast (Finley and Chau, 1991). Through the coordinated activity of multiple enzymes, ubiquitin is covalently added to substrate proteins through the formation of an iso-peptide bond between the C-terminal diglycine motif of ubiquitin and lysine residues on the target (Figure 1) (Hershko and Ciechanover, 1998). This cascade begins with the ATP-dependent attachment of ubiquitin's C-terminal glycine through a thio-ester bond to an active-site cysteine on an Ubiquitin Activating Enzyme (E1). This ubiquitin is then transferred to a Ubiquitin Conjugating Enzyme (E2) through a thio-ester bond. From there, the E2 enzyme will cooperate with a Ubiquitin Ligase (E3) to transfer the ubiquitin molecule to the target lysine on a substrate protein. This last step occurs differently depending on the type of E3 involved, but it is at this step that substrate specificity is believed to occur, with E3 ligases selecting substrates for ubiquitination. However, this view has recently come under some scrutiny, as evidence emerges for a role for E2s in the process of substrate selection (Scaglione et al., 2013).

E3s are typically grouped into three classes, with each defined by the specific protein domains it possesses. These domain-based classes include: (1) Really Interesting New Gene (RING) fingercontaining E3s, (2) Homologous to E6-AP (HECT) domaincontaining E3s, and (3) E3s composed of multiple subunits. RING finger-containing E3s bring the E2 and the substrate protein into sufficiently close proximity for the transfer of the ubiquitin to its target lysine (Lorick et al., 1999). HECT-domain containing proteins possess an active-site cysteine to which the ubiquitin is first transferred from the E2 before being passed to the substrate protein (Huibregtse et al., 1995). In contrast to these single-unit E3 ligases, multi-subunit ligases are composed of multiple adaptor proteins, cofactors, and scaffolding proteins that confer substrate specificity and facilitate ubiquitination (Cardozo and Pagano, 2004). The Skp1/Cul1/F-box (SCF) protein complex and the Anaphase-promoting Complex (APC) are among the best studied of these multi-subunit E3s. SCF complexes can include various combinations of scaffolding proteins called cullins, F-box proteins, and substrate adaptors (Hao et al., 2005). APC is less variable, containing Apc2, Apc11, and either Cdh1 or Cdc20 for substrate recognition (Biggs et al., 2006). Each E3 can recognize multiple substrates; Fbxw1/ $\beta$-TRCP1, for example, has upwards of 40 documented substrates itself (Skaar et al., 2009). Further contributing to the complexity of these multi-subunit E3 ligases is the developmental and spatial restriction of their expression within cells (Pines, 2006). There are estimated to be at least 500 different E3 ligases, with more continuing to be discovered (Ardley and Robinson, 2005).

This highly regulated process adds ubiquitin to target lysines on the substrate, but it can also add other ubiquitin molecules onto lysines of a ubiquitin already conjugated to a substrate. By this process, ubiquitin chains of varying length and composition can be formed. The elongation of ubiquitin chains can occur at any of ubiquitin's own seven lysines, resulting in the formation of different linkage types (Peng et al., 2003). Although all possible linkage types are present in cells, their precise functions remain only partially understood (Xu et al., 2009). Chains formed through the addition of ubiquitin exclusively at lysine 48 (K48) have been recognized to signal protein degradation (Glickman and Ciechanover, 2002), whereas K63-linked ubiquitin chains seem to subserve diverse functions beyond protein degradation (Jacobson et al., 2009). For example, K63-linked chains regulate NF- $\kappa \mathrm{B}$ signaling not by promoting protein degradation but by influencing ubiquitin-dependent protein-protein interactions (Hadian et al., 2011). Elsewhere, however, they have been implicated in promoting the lysosomal degradation of the low density lipoprotein receptor (LDLR) (Zhang et al., 2013) and the epidermal growth factor receptor (EGFR) (Huang et al., 2013). Both K48- and K63-linked chains have been observed to modify kinase activity in response to cellular stress, as have K11-linked chains (Ben-Neriah, 2002; Bertrand et al., 2011). K11-linked chains are critical for cell-cycle regulation and cell division (Matsumoto et al., 2010). Other linkages, including atypical, mixed-type linkages are less well studied, but have been implicated in similar processes within the cell (Ikeda and Dikic, 2008; Husnjak and Dikic, 2012).

The functions thus far attributed to specific chain linkages represent only a fraction of the diverse roles ubiquitin is known to play in cellular processes (Husnjak and Dikic, 2012), many of which do not depend on proteasome function (Mukhopadhyay and Riezman, 2007). Ubiquitination regulates DNA repair (Jackson and Durocher, 2013), protein localization and endocytosis (Haglund et al., 2003; Hicke and Dunn, 2003; Schnell and Hicke, 2003), and protein-protein interactions (Hoege et al., 2002; Moldovan et al., 2007). Free, unanchored chains of ubiquitin molecules are also present in cells and can regulate numerous functions including kinase activation (Xia et al., 2009). The UPS has been also been implicated in the turnover of mRNA, although whether this regulation is direct or indirect remains unclear (Cano et al., 2010). Intriguingly, E3 ligases can 


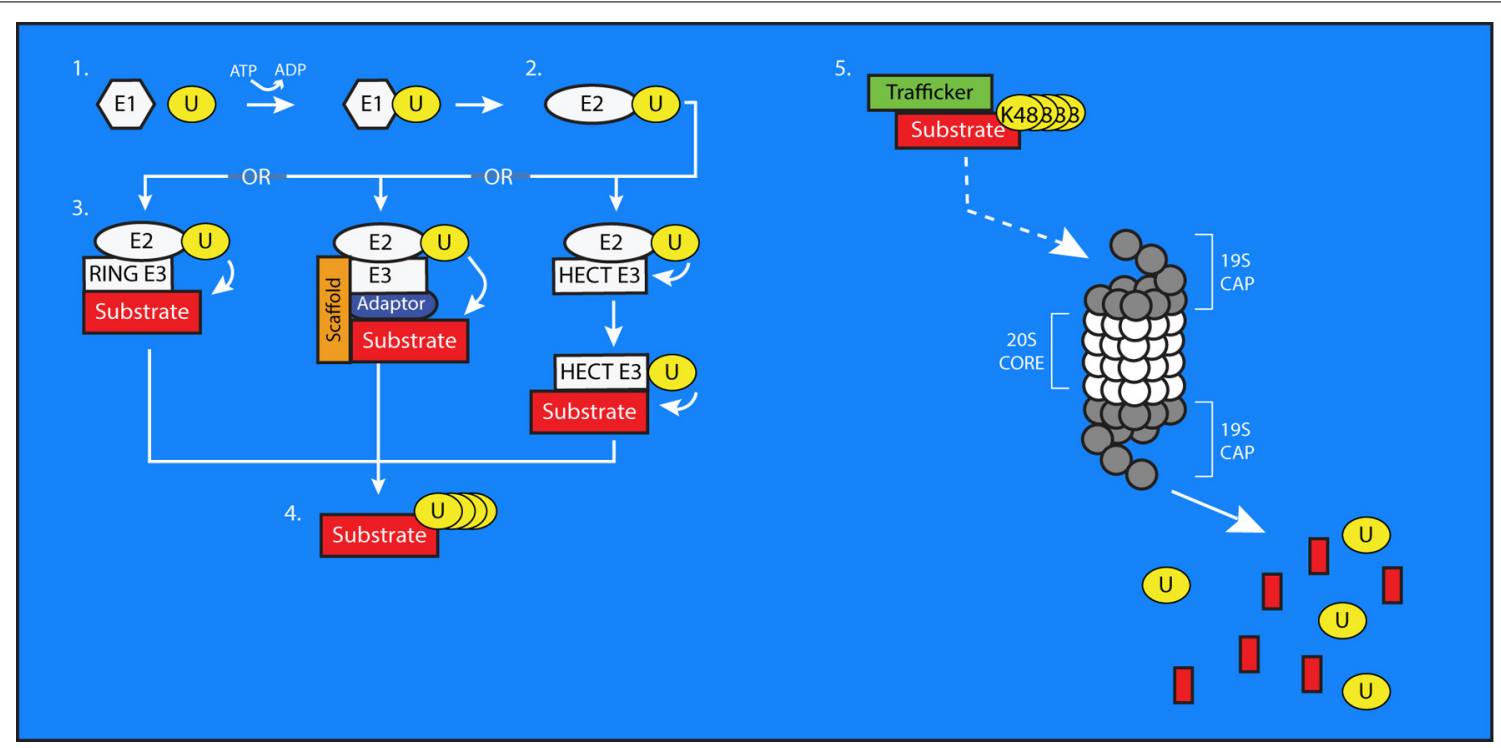

FIGURE 1 | The process of ubiquitin conjugation. 1. Ubiquitin $(U)$ is bound via a thioester bond to the active-site cysteine of an E1 Ubiquitin-Activating enzyme, through a process requiring ATP. 2. The ubiquitin molecule is then passed to an E2 Ubiquitin-Conjugating Enzyme through trans(thio)esterification. 3. An E3 ubiquitin ligase brings the E2 into sufficiently close proximity and correct alignment with a substrate protein to facilitate the transfer of ubiquitin to a target residue. In the case of HECT-type E3s, the ubiquitin is first transferred to an active site cysteine on the E3 before being conjugated to the substrate. E3s can also exist as multi-subunit complexes including scaffolding and adaptor proteins that confer substrate specificity to the process of ubiquitin transfer. 4. Additional ubiquitin molecules can be added onto the first to create polyubiquitin chains on substrate proteins. 5 . The $26 \mathrm{~S}$ proteasome is composed of a cylindrical, proteolytic $20 \mathrm{~S}$ core which is capped at both ends by a $19 \mathrm{~S}$ regulatory cap. Polyubiquitinated substrate proteins, typically bearing K48-linked chains, are targeted to the proteasome by trafficking proteins. The proteasome digests these substrates into smaller peptides and free ubiquitin molecules, which then can be used to modify further substrates. themselves be targeted for ubiquitination, offering an additional level of control for this important pathway (Buschmann et al., 2000; Xiong et al., 2009). The ubiquitination of E3 ligases can result either in their degradation or in the modification of their activity (Scaglione et al., 2011).

Once a substrate is tagged for elimination through the addition of a ubiquitin chain, it must be targeted to the cell's degradation machinery by chaperone proteins that recognize and bind to poly-ubiquitin chains. One such chaperone is Valosin-containing protein (VCP), which has been shown to physically interact with and shuttle poly-ubiquitinated substrates to the proteasome to facilitate their degradation (Figure 1) (Dai and Li, 2001). The proteasome contains a catalytic protein complex referred to as the $20 \mathrm{~S}$ core (Lowe et al., 1995), which is capped at each end by a regulatory protein complex (19S) (Finley, 2009; Zhang et al., 2009). It is responsible for breaking down substrate proteins into small peptides (Hough et al., 1987; Hadari et al., 1992).

The ubiquitination of substrate proteins is a reversible process. The removal of ubiquitin is carried out by De-ubiquitinating Enzymes (DUBs). DUBs play two important roles, allowing for the editing of existing chains (Wilkinson, 1997) and the removal of ubiquitin chains altogether from a substrate. As the presence of ubiquitin chains prevents substrates from entering the proteasome due to spatial restrictions, DUBs play an essential role in determining the rate of protein clearance in cells (Hershko and Ciechanover, 1998; Wilkinson, 2009), and certain DUBs including USP14 are known to associate directly with the19S regulatory complex of the proteasome (Borodovsky et al., 2001).
It is important to consider that while numerous studies report proteasome dysfunction in disease states, proteasomal degradation is only one of several potential outcomes of ubiquitination that may contribute to pathogenesis when impaired. Indeed, there are numerous examples of dysregulated protein handling due to failures in ubiquitination that do not necessarily implicate the proteasome. Whether the effects of proteasomal failure reach upstream to impact the activity and efficacy of E1s, E2s, or E3s is not clear. Given that K48-linked chains are among the most common found in cells (Ziv et al., 2011), it is conceivable that impaired proteolysis could deplete cellular pools of free ubiquitin and thereby induce further dysfunction. Accordingly, an imbalance in ubiquitination/deubiquitination activities may result in improper chain formation, preventing the proteasome from recognizing and handling targeted substrates. To examine these two separate yet related phenomena, it will be helpful to distinguish whether dysfunction occurs in UPS per se or, more broadly in the Ubiquitin Signaling System (USS) which includes the labeling of proteins with ubiquitin for any number of intended outcomes beyond degradation. While impaired clearance characterizes UPS failure, it remains to be seen whether and how the other, non-proteasomal components of the USS contribute to disease processes. One example of this distinction is evident in the ubiquitin-mediated fate of Caspase proteins.

Though the precise methods by which neurons degenerate in disease remain unclear, substantial evidence supports a role for proteases of the Caspase family. For example, activated caspases are elevated in AD patient tissue (Bredesen, 2009). Upon 
activation, caspases can either activate other proteases (initiator caspases) or damage essential components of the cell and promote apoptosis (effector caspases). Sublethal amounts of caspase activation have been linked to synaptic dysfunction in an animal model of AD (D'Amelio et al., 2011). Caspase-mediated effects can be inhibited both by the inactivation of caspase enzyme activity and by their targeted degradation through the proteasome. The X-linked Inhibitor of Apoptosis Protein (XIAP) and its family member cIAP1 are RING-type E3 ligases that directly bind to and target caspases for degradation; XIAP is also able to inhibit the proteolytic activity of caspases (Suzuki et al., 2001; Choi et al., 2009). The regulation of caspases by XIAP is limited, however, in oxidative stress conditions. Both acute and chronic inflammation, which are often associated with disease, elevate the levels of nitric oxide in neurons. This elevation can lead to the aberrant addition of nitric oxide to proteins (nitrosylation). Dysregulated nitrosylation of proteins is evident in several neurodegenerative diseases, including AD (Nakamura et al., 2013). The addition of nitric oxide (nitrosylation) to the active cysteine of XIAP's RING domain inactivates its E3 ligase activity. Nitrosylated XIAP is unable to ubiquitinate caspases and thus unable to inhibit apoptosis (Nakamura et al., 2010). The relative amount of nitrosylated $\mathrm{XIAP}$ is increased in $\mathrm{AD}$ patient tissue, suggesting a role in the accelerated apoptosis observed in disease (Nakamura et al., 2010). Here, then, is one example in which the state of the proteasome in disease is secondary to the decreased ability of E3 ligases to target caspases for degradation. Therefore, it is essential to consider how disease-related proteins are modified by agents of the USS while also examining whether affected neurons can execute the intended consequences of that modification.

\section{UBIQUITINATION IN NEUROPATHOLOGY}

To further illustrate the complexity and fundamental significance of ubiquitin-mediated pathway involvement, we review key findings about the handling of disease-related proteins by the USS and UPS in several of the most common neurodegenerative diseases.

\section{ALZHEIMER'S DISEASE}

Alzheimer's disease is the most common form of dementia and the most common neurodegenerative disorder. Its symptoms include a progressive decline in memory and other cognitive functions. Histologically, AD involves extensive neurodegeneration and loss of synaptic connections, resulting in progressive atrophy of the temporal, frontal and parietal lobes of the cerebral cortex. It is characterized by the hallmark deposition of intracellular, filamentous aggregates mainly consisting of hyper-phosphorylated Tau (neurofibrillary tangles, NFTs) and extracellular plaques rich in Amyloid-Beta (amyloid plaques) (Glenner et al., 1984; Goedert et al., 1988; Wischik et al., 1988). Ubiquitinated forms of Tau and Amyloid-Beta, as well as other ubiquitinated proteins, are major components of these aggregates (Perry et al., 1987). Amyloid-Beta, produced by the cleavage of the Amyloid Precursor Protein (APP), is thought to have numerous deleterious effects on neuronal health and connectivity (Thinakaran and Koo, 2008). Mutations in the genes encoding APP or the presenilin protease enzymes that cleave APP to generate Amyloid-Beta cause earlyonset $\mathrm{AD}$, and support the notion that Amyloid-Beta metabolism is a central component of $\mathrm{AD}$ pathogenesis (Bertram et al., 2010). The generation of hyper-phosphorylated Tau is less clearly understood. It has been suggested that Amyloid-Beta is able to stimulate the kinase GSK3-B, resulting in the aberrant phosphorylation of Tau (Hernandez et al., 2010). The mechanisms governing the synthesis, processing, and degradation of these proteins remain incompletely understood. Inhibition of the proteasome causes an increase in Amyloid-Beta (Kumar et al., 2007), and numerous studies have begun to describe an extensive role for both ubiquitination and the proteasome in the production and handling of APP, Amyloid-Beta, and Tau (Figure 2).

APP is produced in the endoplasmic reticulum (ER). HRD1, an E3 ligase associated with the clearance of newly synthesized proteins through ER-associated degradation (ERAD), has been shown to interact with APP. Decreasing HRD1 expression evokes ER stress and apoptosis, accompanied by the accumulation of APP and Amyloid Beta. The disease relevance of the HRD1/APP relationship is supported by the reduced levels of HRD1 in AD brain tissue (Kaneko et al., 2010). Similarly, the levels of Fbxo2, a brain-enriched E3 ligase substrate adaptor protein also implicated in ERAD, have been reported to be decreased in $\mathrm{AD}$ patient tissues (Gong et al., 2010). Fbxo2 was also found to facilitate the degradation of APP, and a knockout mouse model for Fbxo2 revealed elevated levels of APP and Amyloid Beta in a brain region-specific manner (Atkin et al., 2014).

In the Golgi apparatus, APP is ubiquitinated by unknown E3 ligases stimulated by ubiquilin-1, a protein with chaperone-like properties. This ubiquitination is K63-linked and does not cause the degradation of APP. Instead, it causes the retention of APP in the early secretory pathway, impairing its maturation and delaying its subsequent processing by secretases into Amyloid Beta (El Ayadi et al., 2012). The process by which this ubiquitination of APP is normally removed to allow processing remains unclear. Ubiquilin-1 levels are significantly decreased in AD patient brain tissues, further suggesting a role in $\mathrm{AD}$ pathogenesis (El Ayadi et al., 2012). Single-nucleotide polymorphisms (SNPs) in the UBQLN1 gene have recently been linked to late-onset AD (Stieren et al., 2011).

After being produced and trafficked to the surface, APP is internalized via endocytosis into the endosome and transGolgi network and sequentially cleaved to produce AmyloidBeta (Thinakaran and Koo, 2008). The C-terminus of HSP70 Interacting Protein (CHIP) is an E3 ligase previously associated with polyglutamine neurodegenerative disorders (Miller et al., 2005; Williams et al., 2009). In AD models, CHIP has been shown to interact with Amyloid-Beta in the Golgi, in a manner that increases upon inhibition of the proteasome. Over-expression of CHIP results in a decrease in Amyloid-Beta levels and may stabilize levels of APP (Kumar et al., 2007).

Beyond targeting APP or Amyloid-Beta directly, the USS affects numerous other components of the Amyloid pathway, including the secretase enzymes responsible for the production of Amyloid Beta. FBXW7 (SEL-10) facilitates the ubiquitination of the gamma-secretase component Presenilin 1 (PS1), although this ubiquitination unexpectedly increases Amyloid Beta production through mechanisms that remain unclear (Li et al., 2002). Fbxo2, described above, has also been implicated in the turnover 


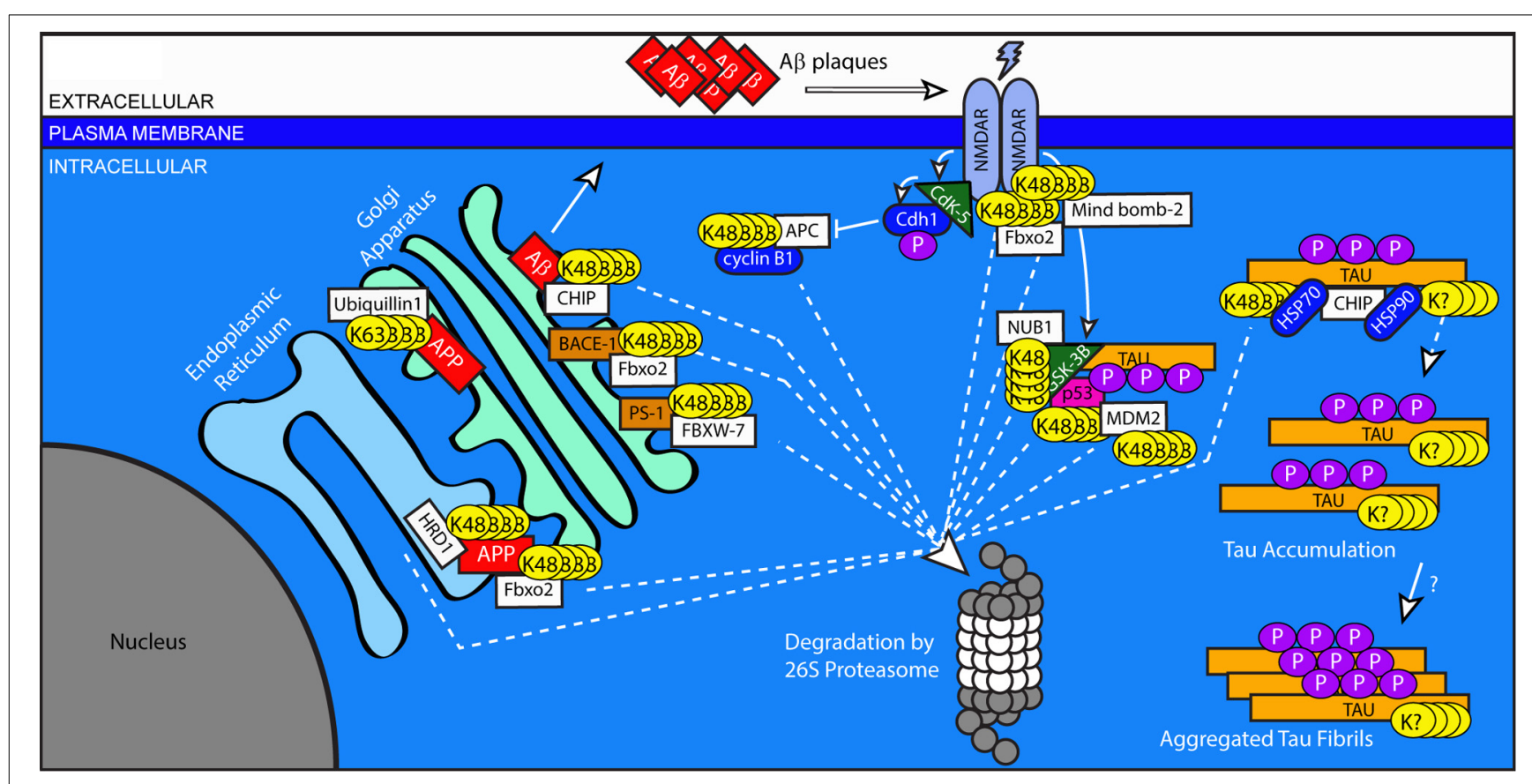

FIGURE 2 | Regulation of protein trafficking, receptor signaling, and protein clearance by ubiquitination in Alzheimer's disease. Improper processing of APP and Tau contribute to the pathology of AD. Excessive or improperly folded APP is cleared from the ER by HDR1 and Fbxo2 through the addition of $\mathrm{K}-48$ linked chains. Ubiquitin-mediated processes are indicated by dashed lines. Maturation of APP is arrested in the early secretory pathway by non-degradative, K-63 linked ubiquitination that is stimulated by Ubiquilin 1. Surface APP is endocytosed to the late Golgi, where it is cleaved by secretases including BACE-1 and PS-1, whose levels are regulated by the E3 ligases $\mathrm{FbxO} 2$ and $\mathrm{FBXW}-7$, respectively. The cleavage of APP results in the production of Amyloid-Beta, which can be targeted for degradation by CHIP. Uncleared Amyloid-Beta is exocytosed to the extracellular space, where it aggregates to form plaques. Amyloid-Beta can influence NMDA receptor signaling. NMDA receptor activation stimulates the kinase $\mathrm{Cdk5}$, which results in the downstream inhibition of the E3 ligase APC and blocks the degradation of cyclin B1. NMDA receptor signaling also increases the activation of GSK3B, which phosphorylates Tau. GSK3B is targeted for degradation by NUB1, which also blocks the interaction between GSK3B and Tau. GSK3B activity is increased by complexing with p53, whose levels are regulated by the E3 ligase MDM2. Under conditions of cellular stress, MDM2 auto-ubiquitinates and targets itself for degradation. The E3 ligase CHIP targets Tau, but can have divergent effects on its handling. When working in combination with Hsp70, CHIP targets Tau for degradation. However, when Hsp90 is involved, CHIP facilitates an alternative ubiquitination of unknown linkage type, resulting in the accumulation of phosphorylated tau. Through an unknown mechanism, this accumulated Tau then forms insoluble protein aggregates. of the Beta-secretase protein BACE1 (Gong et al., 2010). Similarly, overexpression of the E3 ligase Parkin, described below for its role in PD, has been shown to reduce APP expression, Amyloid-Beta burden, and inflammation while also restoring the formation of long-term hippocampal synaptic potentiation in an $\mathrm{AD}$ mouse model (Hong et al., 2014).

The effects of Amyloid-Beta on neurons are numerous, and can also influenced by the complex actions of the USS in more indirect methods than just the degradation of the AmyloidBeta peptide or its precursor. For example, exposure to excess Amyloid-Beta causes diminished Brain-Derived Neurotrophic Factor (BDNF) signaling in $\mathrm{AD}$ patient tissue and mouse models (Peng et al., 2005); however, this diminution can be reversed by the overexpression of the de-ubiquitinating enzyme UCHL-1, which, through an unknown mechanism, restores the trafficking of BDNF receptors (Poon et al., 2013). Intriguingly, UCHL-1 levels are decreased in AD patient brains (Poon et al., 2013).

As another example, the intracellular response to AmyloidBeta is thought to be mediated through numerous proteins including GSK3B, a kinase that is reportedly increased in AD and has Tau as one of its substrates. GSK3B has been investigated as a possible link between the two characteristic protein pathologies of AD (Hernandez et al., 2010). The kinase activity of GSK3B is enhanced by forming a complex with the tumor suppressor protein p53. Under normal conditions, this interaction is limited by the degradation of p53 by the E3 ligase Mouse double minute 2 homolog (MDM2). Under conditions of cellular stress, however, MDM2 levels are decreased, leading to the increased association of GSK3B and p53. This enhancement is thought to contribute to the hyperphosphorylation of Tau seen in $\mathrm{AD}$ (Proctor and Gray, 2010). The observed decrease in MDM2 under conditions of stress actually stems from its own governance by the UPS. Under normal conditions, MDM2 is modified by the small, ubiquitin-like modifier protein SUMO. Sumoylation of MDM2 prevents its auto-ubiquitination. Under conditions of cellular stress, sumoylation of MDM2 is diminished, causing it to become auto-ubiquitinated which then triggers its own degradation by the proteasome (Buschmann et al., 2000). The level of GSK3B in neurons is also mediated by yet another E3-ligase, Nedd8 ultimate buster 1 (NUB1). NUB1 directly binds to GSK3B and promotes its degradation by the proteasome, while also inhibiting the interaction between GSK3B and Tau. NUB1 activity 
thereby diminishes the levels of hyper-phosphorylated Tau and Tau aggregates (Richet et al., 2012).

NUB1 was originally identified for its role in regulating Nedd8 (Kamitani et al., 2001; Kito et al., 2001). Nedd8 is a small signaling protein similar to ubiquitin both in structure (approximately 60\% identity and $80 \%$ homology to human ubiquitin) and in function (Kumar et al., 1993; Kamitani et al., 2001). The conjugation of Nedd 8, "neddylation," to cullin proteins promotes the ubiquitination activity of SCF complexes (Duda et al., 2008). Nedd8 also modifies other proteins, including transmembrane proteins such as APP, and may influence their degradation (Chen et al., 2012). Dysregulated clearance of Neddylated proteins in disease states is evinced by the accumulation of Nedd8 in ubiquitin-positive tau filamentous inclusions in some cases of AD and in Lewy bodies in PD (Dil Kuazi et al., 2003).

CHIP, described above for its role in the turnover of Amyloid-Beta, has also been shown to play a role in regulating phosphorylated Tau. Through its interaction with two heat-shock-induced proteins, Hsp70 and Hsp90, CHIP is able to ubiquitinate phosphorylated Tau. Under normal conditions, this ubiquitination leads to an accumulation of ubiquitinated tau, which then becomes aggregated into high molecular-weight, detergent-insoluble aggregates. CHIP immunoreactivity decorates NFTs in several tauopathies, including $\mathrm{AD}$ (Petrucelli et al., 2004). However, over-expression of Hsp70 shifts the handling of ubiquitinated Tau toward a pathway of clearance through the UPS, rather than aggregation, and reduces Tau levels in vitro (Petrucelli et al., 2004). Intriguingly, in vitro the ubiquitination of Tau also is carried out in an E3-ligase independent manner by the E2 Ube2w (Scaglione et al., 2013). Ube2w, whose levels are increased under cellular stress, also ubiquitinates CHIP and regulates its activity (Scaglione et al., 2011). Additionally, a role for CHIP in the ubiquitin-mediated turnover of caspases has been described. Mice that lack CHIP show increased levels of cleaved and uncleaved caspase-3 (Dickey et al., 2006).

Although not considered causative themselves, additional proteins have been shown to exacerbate disease pathogenesis, and are similarly subject to regulation by ubiquitination. NMDA receptors are ionotropic glutamate receptors whose regulated conductance of calcium into postsynaptic sites has been linked to learning and memory. Aberrant activation and signaling of these receptors has been implicated in numerous disease processes, including AD (Hardingham and Bading, 2010). It has been suggested that the Amyloid-Beta-induced loss of synapses requires the activation of extra-synaptic NMDA receptors containing the GluN2B subunit (Shankar et al., 2007; Talantova et al., 2013), underscoring the importance of regulating NMDA receptor levels and localization in AD pathology. GluN2B is ubiquitinated in response to synaptic activity by the E3 ligase Mind Bomb-2 (Jurd et al., 2008). Fbxo2, described above for its regulation of APP, also regulates the levels of NMDA receptors in vitro by facilitating the activity-dependent ubiquitination and elimination of the NMDA receptor subunit GluN1 (Kato et al., 2005).

The downstream effects of NMDA receptor activation on cell health include the regulation of ubiquitin-dependent pathways. In one example, following NMDA receptor activation, the cyclindependent kinase 5 (Cdk5) phosphorylates Cdh1, a key regulator of the E3 ligase complex APC; in doing so, the turnover of its cyclin B1 by APC is inhibited, promoting neurotoxicity following NMDA receptor activation (Maestre et al., 2008).

\section{PARKINSON'S DISEASE}

Parkinson's disease is the second most common neurodegenerative disease and the most common neurodegenerative movement disorder. It is characterized by progressive abnormalities in gait and posture, as well as difficulty initiating and completing voluntary and involuntary movements. Histopathologically, PD involves the loss of dopaminergic neurons of the substantia nigra and locus ceruleus accompanied by astrocytosis and increased numbers of microglia. Throughout the brainstem of PD patients, proteinaceous intracellular aggregates called Lewy bodies can be found, comprised primarily of alpha-synuclein. With slightly altered appearance, these synuclein-containing aggregates can be seen in other brain regions, and the question of their contribution to disease pathogenesis remains an area of intense study (Syme et al., 2002). Although the majority of PD cases are of sporadic origin, the small fraction of inherited cases has provided valuable insight into the role of the USS and UPS in PD pathology (Figure 3).

Mutations in alpha-synuclein have been described in cases of familial PD (Kruger et al., 1998; Riess et al., 1998), and the proteasome is at least partially responsible for the turnover of this protein (Shimura et al., 2001). Proteasome dysfunction is reported in the substantia nigra in PD, and proteasomal inhibition itself can cause the formation of protein inclusions and eventual degeneration of neurons in the substantia nigra in rats, although with some inconsistency (McNaught and Jenner, 2001; McNaught et al., 2002; McNaught and Olanow, 2006). The expression of mutant alpha-synuclein induces the formation of filaments which interact directly with the $20 \mathrm{~S}$ core of the proteasome and decrease its proteolytic activity (Lindersson et al., 2004). This deficit in proteasome function is ameliorated by the concomitant expression of the E3 ligase Parkin (Petrucelli et al., 2002).

Of patients with inherited PD, nearly 40 percent of those with an early onset of symptoms have mutations in the gene encoding Parkin (Lucking et al., 2000). First described in Japan, multiple mutations in Parkin have now been described in one or both alleles (Khan et al., 2003). While mutations in alpha-synuclein cause autosomal dominant PD, mutations in Parkin cause autosomal recessive PD. These mutations result in the loss of Parkin function, one aspect of which is to regulate the ubiquitination of alpha-synuclein. Because the accumulation of ubiquitinated alpha-synuclein is evident in both familial and sporadic PD, Parkin dysfunction may also play a role in idiopathic PD and the formation of Lewy bodies (Shimura et al., 2000; Hardy, 2003). Consistent with this view, targeted expression of mutant Parkin in disease-related brain regions of animal models yields similar pathologies to those observed in PD (Lu et al., 2009).

Parkin is also involved in the intricate regulation of prosurvival signaling through the Akt pathway by Epidermal Growth Factor (EGF) (Fallon et al., 2006). EGF-Akt signaling occurs through EGFRs which are decreased in disease-related brain regions of patients with PD (Iwakura et al., 2005). Accordingly, increased activation of EGFR in an animal model of PD prevents 


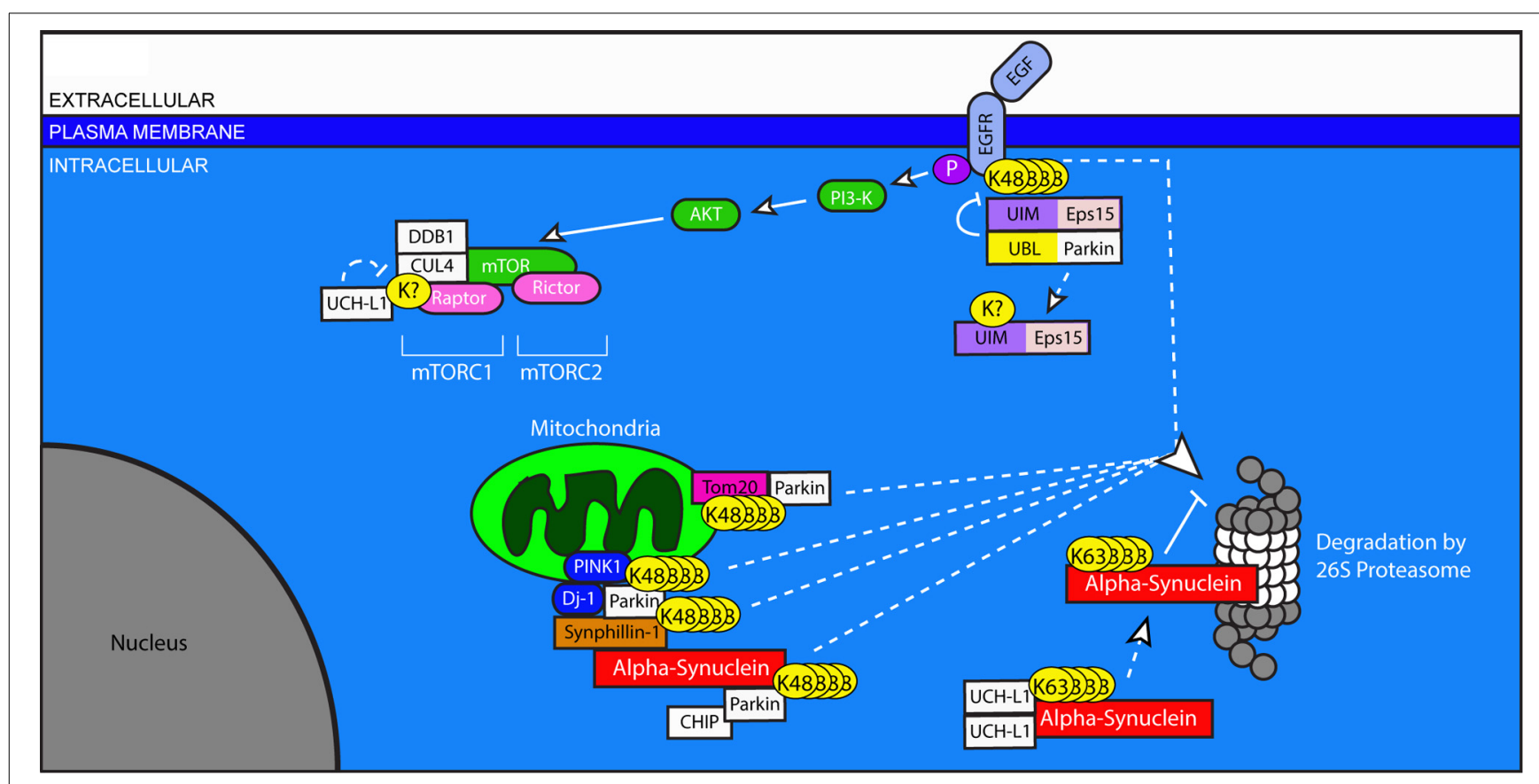

FIGURE 3 | Ubiquitination in pro-survival pathways, mitochondria stability, and protein clearance in Parkinson's disease. Dysregulation of Parkin and UCHL1, both of which are associated with PD, has widespread effects on neuronal health. The Epidermal Growth Factor (EGF) binds to EGFR and initiates pro-survival signaling through the Akt and mTOR pathways. Ligand-binding to EGFR stimulates its ubiquitination, which allows for its UIM-dependent recognition by Eps15. Eps15 internalizes EGFR, allowing it to be trafficked to the proteasome for degradation. The EGFR-Eps15 interaction is blocked by the interaction of the UBL of the E3 ligase Parkin with the UIM of Eps15; this interaction increases Parkin's ligase activity, causing Eps15 to become ubiquitinated and dissociated from its
UIM-dependent interactors. Downstream of EGFR signaling, mTOR's participation in the protein complex mTORC1 requires the ubiquitination of Raptor by DDB1 and Cul4. This ubiquitination is undone by the de-ubiquitinating enzyme UCHL1. Parkin also plays a role in the degradation of mitochondrial outer membrane proteins including Tom20, and through its involvement with PINK1 and Dj-1, facilitates the degradation of Synphilin-1 and itself. Synphilin interacts with alpha-synuclein, which can be degraded by Parkin in association with CHIP. Dimerized UCHL1 may also modify alpha-synuclein, though the result is non-degradative, K-63 linked ubiquitination which promotes its accumulation. Accumulated alpha-synuclein binds to the $20 \mathrm{~S}$ core of the proteasome and inhibits proteasome function. the loss of dopaminergic neurons (Iwakura et al., 2005). EGF signaling is regulated by ubiquitin in several ways. Ligand binding of EGFR stimulates Akt signaling, but triggers the endocytosis and degradation of EGFR, thereby limiting the extent of EGF signaling. This process is mediated by the activity-dependent ubiquitination of EGFR by an unknown E3 ligase, which makes it eligible for recognition by the ubiquitin-interacting motif (UIM) of the EGFR Protein tyrosine kinase Substrate \#15, Eps15. Interaction with Eps15 is necessary for the internalization of EGFR, as Eps15 links ubiquitinated EGFRs to the machinery which traffics them to the proteasome for degradation (van Bergen En Henegouwen, 2009). Parkin, which contains an amino-terminal ubiquitin-like (UBL) domain, blocks the Eps15-EGFR interaction by binding to the UIM of Eps15 through this UBL domain, and then facilitating the ubiquitination of Eps15. In this manner, EGFR internalization is prevented, and EGF signaling and activation of pro-survival pathways are enhanced. But interaction between Eps-15 and Parkin suggests yet a further level of ubiquitindependent regulation. Eps-15 promotes its own ubiquitination by stimulating Parkin's E3 ligase activity upon interaction. This ubiquitination, which is believed to be K63-linked, prevents the interaction of ubiquitinated Eps15 with other ubiquitinated proteins such as EGFR and Parkin itself. Notably, Parkin deficiency causes a reduction in EGF signaling (Fallon et al., 2006). Here, again, dysfunctional ubiquitin signaling, independent of proteasomal cleavage, is able to regulate the health of neurons in a disease context.

Parkin has been shown to function as part of a macromolecular E3 ligase complex which includes the pten-induced kinase (PINK1) and the peptidase Dj-1 (Xiong et al., 2009). Mutations in both PINK1 and Dj-1 cause hereditary PD (Abou-Sleiman et al., 2003; Valente et al., 2004). Together, these proteins facilitate the degradation of Parkin substrates. Synphillin-1, which interacts with alpha-synuclein and is also present in Lewy bodies, is one such substrate, as is Parkin itself (Xiong et al., 2009). Additionally, the interaction between PINK1 and Parkin facilitates the degradation and turnover of mitochondria (Greene et al., 2003; Vincow et al., 2013). In order to do so, Parkin targets proteins in the outer mitochondrial membrane for degradation, including Tom20 (Yoshii et al., 2011). These findings suggest that Parkin dysfunction may contribute to global cellular health problems, even beyond the accumulation of alpha-synuclein and synphillin-1.

Rare mutations associated with familial, early-onset PD are also found in the de-ubiquitinating enzyme UCH-L1, described above for its role in AD (Das et al., 2006). These disease-associated 
mutations reduce the DUB activity of UCHL1. UCH-L1's role is significant for the health and function of neurons through its regulation of substrates involved in governing mRNA transcription, protein translation, synaptic plasticity, and pro-survival signaling. These processes are potently influenced by the activity of a serine/threonine protein kinase originally identified for its susceptibility to inhibition by Rapamycin, the Mammalian Target of Rapamycin, mTOR (Sabatini et al., 1994; Hay and Sonenberg, 2004; Ghosh et al., 2008; Hoeffer and Klann, 2010). Intriguingly, mTOR function requires both the correct ubiquitination of interacting proteins and proteasome activity (Ghosh et al., 2008; Quy et al., 2013). mTOR asserts its effects through the formation of large protein complexes. mTOR can function in combination with Raptor (mTOR Complex 1 or mTORC1) or Rictor (mTORC2). mTORC1 regulates transcription and is important for local protein synthesis, a necessary component of several types of synaptic plasticity. mTORC2, on the other hand, influences Akt signaling, cytoskeletal dynamics, and actin polymerization (Costa-Mattioli and Monteggia, 2013). The balance between mTORC1 and mTORC2 formation depends on the interaction of Raptor with a multi-subunit E3 ligase composed of DNA Damage-Binding Protein (DDB1), Cullin 4A (CUL4), and the RING-type E3 ligase RING box 1 (RBX1) (Ghosh et al., 2008). Although the exact mechanism is still unclear, the DDB1-CUL4 complex appears to ubiquitinate Raptor in a manner that facilitates its incorporation into the mTORC1 complex including DDB1, CUL4, Raptor, and mTOR (Ghosh et al., 2008). UCHL1 deubiquitinates Raptor, thereby destabilizing mTORC1 complex formation and shifting the balance toward mTORC2-dependent signaling (Hussain et al., 2013). This shift may have a significant impact on the ability of neurons to modify their synaptic content to promote learning and memory, and may also represent a neuroprotective response mechanism.

The loss of UCHL1's DUB activity results in an accumulation of alpha-synuclein at presynaptic terminals rather than increased clearance (Cartier et al., 2012). Surprisingly, UCH-L1 had been proposed to act as an E3 ligase when it self-dimerizes; this new activity is independent of the state of UCHL1's DUB activity (Liu et al., 2002). Acting as an E3 ligase, UCHL1 causes the K63-linked ubiquitination of alpha-synuclein, which, in turn, worsens PD pathology (Liu et al., 2002). Accordingly, a mutant form of UCH-L1 with decreased E3 ligase activity upon dimerization, but normal DUB activity, decreases PD pathogenesis (Liu et al., 2002). The consequences of UCHL1's ubiquitination of alpha-synuclein remain unclear.

There have been several ubiquitin-linked proteins whose involvement in neurotoxicity overlaps between $\mathrm{AD}$ and $\mathrm{PD}$. Of those described above, CHIP, MDM2, and HRD1 support the importance of the UPS in pathological mechanisms in multiple disease states. CHIP also interacts with Parkin and stimulates its ligase activity (Imai et al., 2002). Even without additional insult, the down-regulation of MDM2 is toxic to dopaminergic neurons (Nair et al., 2006). And HRD1 levels are increased in dopaminergic neurons under conditions of neurotoxicity, suggesting a role in the response to cellular stress (Mei and Niu, 2010).

\section{AMYOTROPHIC LATERAL SCLEROSIS}

Amyotrophic Lateral Sclerosis (ALS) is the most common fatal neurodegenerative disease affecting motor neurons. The loss of motor neurons in the brain and spinal cord of ALS patients typically results in progressive paralysis and death within a few years of onset. Non-motor pathologies, particularly cognitive deficits, can also accompany motor deficits. Histopathologically, ubiquitin-rich cytoplasmic inclusions appear in the remaining motor neurons of ALS patients, accompanied by marked gliosis. Ubiquitin-positive inclusions can also be observed in cortical brain regions, consistent with the observed cognitive decline in many ALS patients (Lowe, 1994; Walling, 1999). Sporadic ALS (SALS) represents greater than 90 percent of all ALS cases, with familial ALS (FALS) accounting for the remaining $<10$ percent. The etiology of ALS remains unclear, and what is known to date has been determined largely through the study of genes originally identified as mutated in FALS. Importantly, the disease genes that cause FALS are also found mutated in some SALS cases, and the histopathologies of familial and sporadic cases are essentially indistinguishable (Andersen and Al-Chalabi, 2011), suggesting that studies of FALS will offer useful insight into all forms of ALS. Among the disease genes associated with FALS, mutations in the gene encoding Superoxide Dismutase 1 (SOD1) were described first (Rosen et al., 1993), and mutations in the Transactivation Response DNA-binding protein 43 (TDP-43) are among the most common (Gitcho et al., 2008). Recently, genome-wide association studies revealed a large hexanucleotide expansion-upwards of 1600 repeats-within the non-coding region of the C9ORF72 gene to be causative in a Finnish cohort (Laaksovirta et al., 2010). Numerous other studies have now observed this expansion in 20-50 percent of FALS cases, making it the most common cause (Boeve et al., 2012; Chio et al., 2012; Simon-Sanchez et al., 2012). The protein products of these genes accumulate in ubiquitinpositive inclusions in disease-related neuronal populations, and the mechanisms of their turnover and clearance provide insight into the importance of the UPS in ALS (Figure 4).

SOD1 plays an important role in the elimination of free superoxide radicals. Its expression is regulated by several agents of the UPS. The canonical HECT-type E3 ligase E6-AP directly binds to and ubiquitinates SOD1 (Mishra et al., 2013). Levels of E6-AP are decreased prior to the onset of neurodegeneration in a mouse model of ALS expressing mutant SOD1, and overexpression of E6-AP reduces the aggregation of mutant SOD1 in vitro (Mishra et al., 2013). NEDL1, a homolog of E6-AP, is reported to selectively bind to mutant SOD1 but not wildtype SOD1, facilitating its ubiquitination and clearance (Miyazaki et al., 2004). NEDL1 is thought to function in concert with the endoplasmic reticulum translocon-associated protein TRAP- $\delta$, suggesting a role for NEDLlin the ERAD of mutant SOD1 (Kunst et al., 1997). The interaction between NEDL1 and mutant SOD1 increases with disease severity, and NEDL1 immunoreactivity is observed in SOD1-positive inclusions in human spinal cord tissue from FALS patients (Miyazaki et al., 2004). Also reportedly present in SOD1-positive inclusions is the RING-finger type E3 ligase Dorfin, which shares NEDL1's selectivity in ubiquitinating mutant, but not wild-type, SOD1 (Niwa et al., 2002). Over-Expression of Dorfin in a mouse model of FALS reduces 


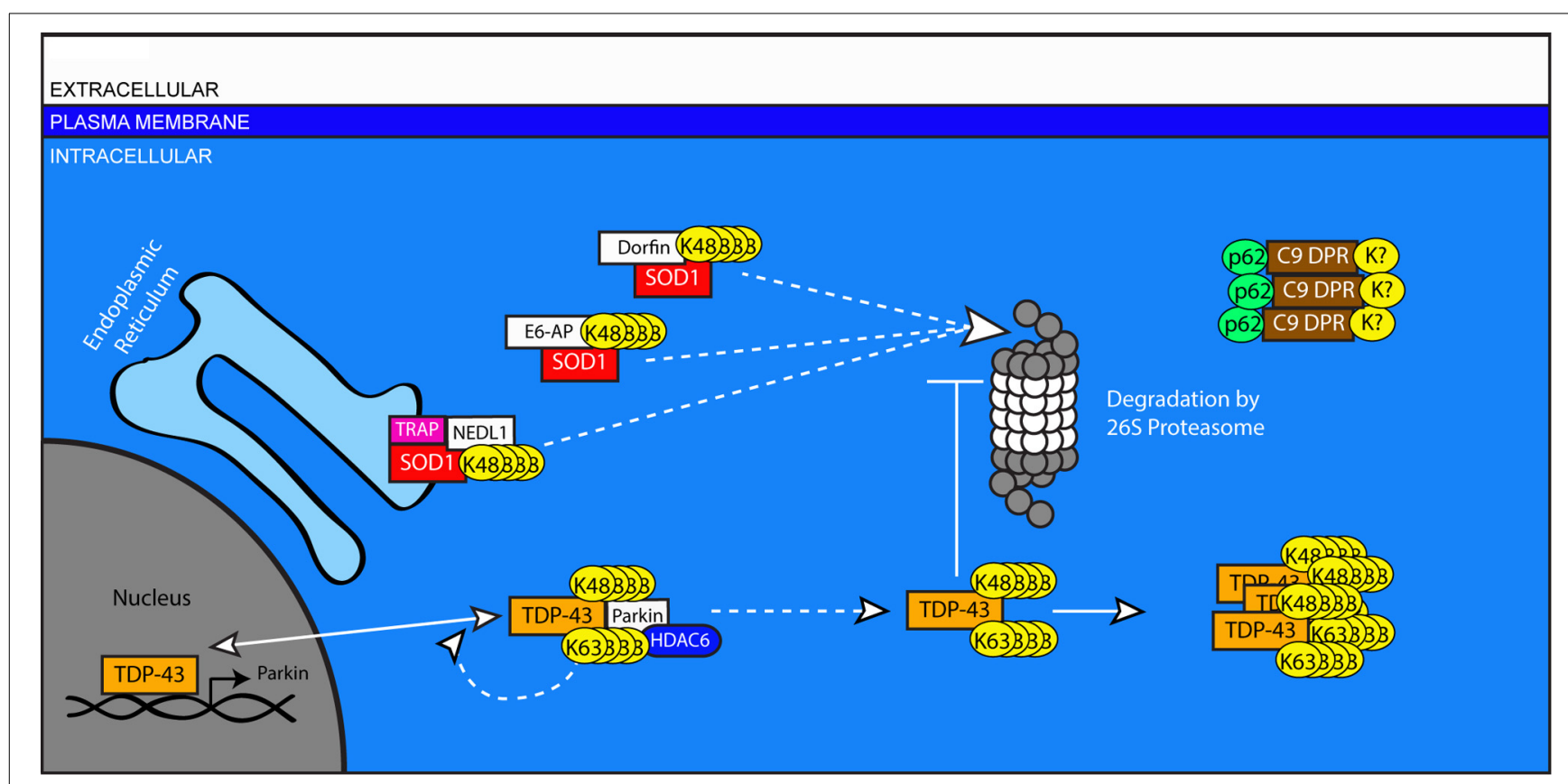

FIGURE 4 | A role for ubiquitination in the pathogenesis of Amyotrophic Lateral Sclerosis. Impaired turnover of SOD1 and TPD-43 are implicated in the etiology of ALS. Mutated or excess SOD1 in the ER is targeted for degradation by the E3 ligase NEDL1 via the translocon protein TRAP. SOD1 in the cytosol is targeted by the canonical HECT-type E3 ligase, E6-AP, and the RING-type E3 Dorfin. TDP-43 can be ubiquitinated by Parkin in association with HDAC6. This modification can include both K48 and K63-linked chains and does not lead to the degradation of TDP-43, instead increasing the proportion of TDP-43 in the cytosol. In the nucleus, TDP-43 regulates the transcription of genes including Parkin. In the cytosol, accumulated TDP-43 can inhibit the proteasome and form protein aggregates. In cases associated with mutations in the C9ORF72 gene, aggregates of DPR proteins are present with ubiquitin- and p62-positive immunoreactivity, but do no colocalize with TPD-43. expression and aggregation of SOD1 while also diminishing motor neuron degeneration (Sone et al., 2010).

The protein TDP-43, extensively aggregated in many in ALS cases, normally has a predominantly nuclear localization. It has two RNA binding domains and has been implicated in RNA splicing and trafficking (Buratti and Baralle, 2001, 2010). Ubiquitinated TDP-43 is a major component of cytoplasmic inclusions in ALS (Neumann et al., 2006). Mutations associated with ALS result in the redistribution of TDP-43 from the nucleus to the cytoplasm (Igaz et al., 2011), although the precise mechanisms by which TDP-43 contributes to ALS pathogenesis remain the subject of intensive study (Janssens and Van Broeckhoven, 2013). TDP-43 expression inhibits proteasome function and increases levels of Parkin mRNA and protein (Hebron et al., 2013) by binding to Parkin mRNA (Polymenidou et al., 2011). Parkin, in turn, is able to mediate both K48 and K63-linked ubiquitination of TDP-43, though this modification does not cause a reduction in the levels of TDP-43 (Hebron et al., 2013). TDP-43 is unlike other substrates of Parkin-dependent K63-linked ubiquitination, which are targeted for degradation through the autophagic pathway (Olzmann and Chin, 2008). The interaction between TDP-43 and Parkin requires the histone deacetylase protein HDAC6 and promotes the translocation of TDP-43 from the nucleus to the cytoplasm (Hebron et al., 2013).

In C9ORF72-related ALS cases, TDP-43 is similarly present in ubiquitin-positive, cytoplasmic aggregates (Mackenzie et al., 2014). However, a second ubiquitin-positive pathology is also observed: ubiquitin- and p62-positive inclusions that are TDP-43 negative, but stain positive for dipeptide products of abnormal transcripts from the hexanucleotide repeats in C9ORF72 (Mackenzie et al., 2014). These dipeptide-repeat (DPR) products are made by unconventional, repeat-associated, non-ATG initiated (RAN) translation of transcripts containing the hexanucleotide repeat expansion (Ash et al., 2013). The pathogenic contribution of these dipeptide products is as yet unclear, but their extensive colocalization with ubiquitin and p62 may suggest a failed attempt by the cells to clear them and the toxic response they may evoke (van Blitterswijk et al., 2012).

\section{HUNTINGTON'S DISEASE}

Huntington's disease is the most common of the polyglutamine (polyQ) disorders. While polyglutamine repeats are common motifs that may facilitate protein-protein interactions, expansion of these repeats is associated with at least nine different neurodegenerative disorders (Ross, 1995; Orr, 2012). The threshold length at which this expansion begins to elicit adverse effects varies among these diseases, determined in part by the specific protein context neighboring the repeat in the expanded protein (Robertson et al., 2011). Expansion of the CAG repeat in exon 1 of the gene coding for the Huntingtin protein increases the length of the polyglutamine domain (Myers et al., 1993; Snell et al., 1993). The repeat length threshold for disease in HD is 38 or more repeats (Chong et al., 1997), with longer repeats causing earlier onset and more severe disease. Symptoms of HD include 
progressive cognitive impairment, mood disorder and other psychiatric symptoms, and highly disordered movement and motor control, including abnormal movements such as chorea. These progressive symptoms lead to mortality within 20 years of onset (Walker, 2007). Histopathologically, HD is characterized by the degeneration of striatal and cortical neurons and the presence of intraneuronal, intranuclear aggregates, and dystrophic neurites. Both of these latter features are marked by the presence of ubiquitinated Huntingtin. These aggregates can be found in cortical and striatal neurons, with some variance in cortical localization related to the age of onset (DiFiglia et al., 1997).

The normal function of Huntingtin remains unknown. Structural analyses and numerous other studies have led scientists to propose several functions including intracellular protein trafficking, modulation of gene transcription, and regulation of scaffolding proteins and NMDA receptors at the synapse (Cattaneo et al., 2005; Parsons et al., 2013). NMDA receptors are improperly localized to extra-synaptic sites in $\mathrm{HD}$, and their signaling at those sites contributes to the onset of symptoms in HD animal models (Milnerwood et al., 2010; Gladding et al., 2012). This mislocalization decreases synaptic NMDA receptor activation, which has been shown to promote Huntingtin aggregation and neuronal survival (Okamoto et al., 2009). Whether HD arises exclusively from a toxic gain of function for mutant Huntingtin or from an additional partial loss of normal Huntingtin function remains unclear. In either case, ubiquitin plays a significant role in the handling of normal and mutant Huntingtin protein (Figure 5).

The presence of ubiquitinated Huntingtin suggests a failure of the UPS. Huntingtin is ubiquitinated (Kalchman et al., 1996), but it has been proposed that the proteasome may be unable to process expanded polyglutamine stretches, resulting instead in the accumulation of peptide fragments containing polyglutamine (Venkatraman et al., 2004). The fate of these peptide fragments is unclear, but they may remain associated with the proteasome and inhibit its function (Holmberg et al., 2004; Raspe et al., 2009). Intriguingly, components of the UPS, including proteasomes, have been identified within Huntingtin aggregates (Suhr et al., 2001). This may represent deleterious proteasomal sequestration in aggregates, even though aggregation of mutant Huntingtin may itself be neuroprotective (Holmberg et al., 2004; Okamoto et al., 2009). The idea that Huntingtin-induced pathology includes a deficiency in UPS-mediated clearance is supported by the beneficial effects observed following efforts to increase proteasomal activity in models of HD (Seo et al., 2007). The upregulation of UPS agents through the action of histone deacetylase inhibitors may also improve the aggregation phenotype of HD model mice (Jia et al., 2012).

The precise mechanisms by which Huntingtin is ubiquitinated are not well understood. It is unclear whether, like TDP-43, ubiquitination of Huntingtin includes both K48 and K63 linkages. Most studies investigating this question have used models overexpressing a fragment of Huntingtin with a polyQ expansion. While such over-expression models induce aggregation and toxicity, their physiological relevance to the human disease state remains an area of some debate. That said, in these model systems several components of the UPS contribute to the clearance of mutant Huntingtin. HRD1, described above for its role in several diseases, is implicated in the clearance of mutant Huntingtin. The activity of HRD1 increases with Huntingtin polyQ expansion length, suggesting that HRD1 regulation may not typically handle normal, unexpanded Huntingtin (Yang et al., 2007). The Tumor Necrosis Receptor Associated Factor 6 (TRAF6) is an E3ligase which binds to both unexpanded and mutant Huntingtin and facilitates non-canonical ubiquitination through K6, K27, and K29-linked chains (Zucchelli et al., 2011). The physiological role of this modification is unclear, but it promotes the aggregation of mutant Huntingtin without changing the localization of the wild-type protein. Additionally, NUB1, described above for its role in $\mathrm{AD}$, works in conjunction with Cullin 3 to facilitate the ubiquitination and clearance of mutant Huntingtin (Lu et al., 2013).

Sumoylation also can regulate $\mathrm{HD}$ pathogenesis. Rhes, a striatal protein which acts as a SUMO E3 ligase, binds to mutant Huntingtin selectively and facilitates its sumoylation (Subramaniam et al., 2009). The sumoylation of mutant Huntingtin decreases its aggregation; however, disaggregated, sumoylated, mutant Huntingtin inhibits transcription, increases cytotoxicity through Caspase-3, and may impair the induction of autophagy (Choo et al., 2004; Steffan et al., 2004; Mealer et al., 2013).

Huntingtin is also reported to interact with the E2 enzyme hE2-25k (Ube2K) (Kalchman et al., 1996). The presence of Ube2k immunoreactivity in HD patient brains has been observed, and the Huntingtin-Ube2k interaction promotes aggregation and cytotoxicity in a manner that requires E2 catalytic function (de Pril et al., 2007). Ube2k has been shown to interact with numerous RING-finger E3 ligases (Lee et al., 2001). It is possible that Ube25k cleaves the polyubiquitin chains attached to Huntingtin to an extent that degradation is no longer signaled.

\section{CONCLUSIONS: TOO BIG NOT TO FAIL}

Befitting its extensive contributions to a wide range of cellular processes, the systems of protein ubiquitination and ubiquitindependent clearance are implicated at many levels of the most common neurodegenerative disorders. Is this implied involvement in disease incidental, or does dysregulated ubiquitination and clearance represent an inevitable and common pathway for the worsening of all neurodegenerative diseases? Because alterations in ubiquitin-dependent gene transcription, translation, control of protein quality and maturation, trafficking, mitochondrial turnover, and the handling of protein-protein interactions are found in combination in neurodegenerative disease, it seems likely that dysregulated ubiquitination will not remain limited to a single ubiquitin-dependent process in a given disease. Instead, the UPS and USS will be widely and progressively involved. To what degree this involvement might begin the pathogenic cascade is currently unclear. But based on the studies reviewed here, it seems more likely that through a complex web of dysfunction in the UPS and USS, involvement of these systems causes the pathogenicity of aberrant proteins to diversify and flourish, affecting additional systems and promoting the loss of synapses and cell death. As questions remain about the mechanism by which the deposition of abnormal protein progresses through regions of a diseased brain, mounting evidence strongly supports the view that this 


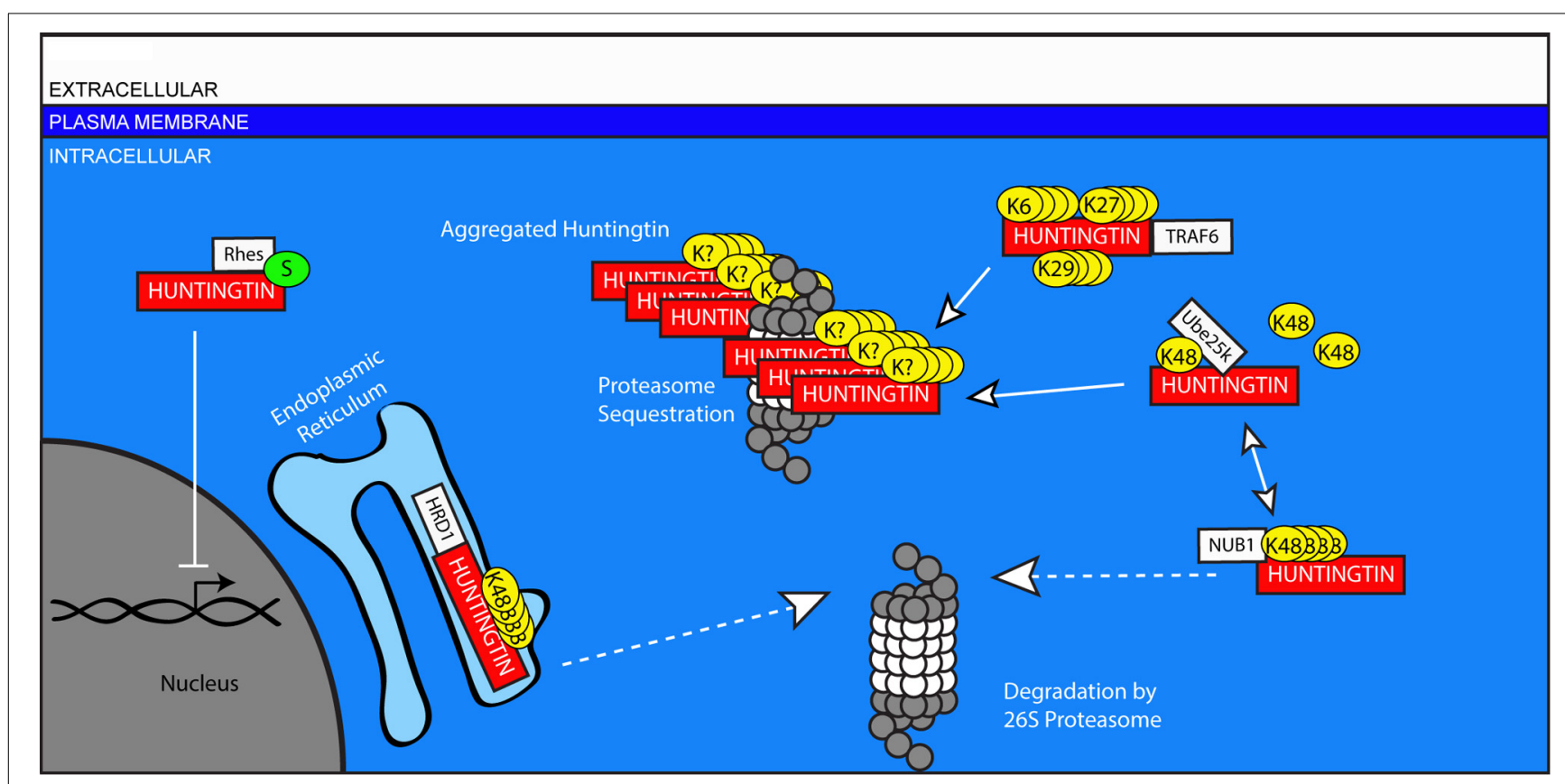

FIGURE 5 | Ubiquitin-mediated handling of the pathologic Huntingtin protein in Huntington's disease. The Huntingtin protein is improperly cleared from neurons in HD. Mutant Huntingtin can be targeted for degradation in the ER by HRD1, and in the cytosol by NUB1. However, this ubiquitination can be edited by UCHL1, inhibiting the degradation of Huntingtin and promoting its aggregation in the cytosol. Traf6 facilitates the non-canonical ubiquitination of Huntingtin through the formation of K6, K27, and K29-linked polyubiquitin chains, and these modifications selectively promote the aggregation of mutant Huntingtin. Aggregates of mutant Huntingtin include components of the UPS including proteasomes. Rhes promotes the sumoylation of Huntingtin, which reduces its aggregation, but causes sumoylated, mutant Huntingtin to interfere with other cellular processes including gene transcription in the nucleus. spread occurs within the context of weakening protein quality control and ubiquitin-mediated pathways.

The UPS is not alone in its handling of unwanted or toxic proteins. The autophagic system is the other major pathway by which protein clearance is achieved. Autophagy especially regulates the turnover of organelles and aggregated protein species, and accordingly its role in neurodegenerative disease has been extensively pursued. Upon failure of the proteasome, autophagic mechanisms can be induced as a compensatory response to UPS inhibition in numerous neurodegenerative diseases (GarciaArencibia et al., 2010; Metcalf et al., 2012; Nixon, 2013). Further activation of autophagic mechanisms through pharmacologic or genetic manipulation has proven useful as a therapeutic intervention in model systems (Hochfeld et al., 2013). It seems evident, however, from the continued accumulation of ubiquitin-positive proteins in neurodegeneration, that autophagic induction is not sufficient to overcome this failure. Moreover, it is unclear what effect sustained, heightened autophagy might have on already weakened neurons.

The overlapping involvement of certain E3 ligases like HRD1, NUB1, and CHIP not only speaks to their significance as key regulators of proteostasis but also nominates them as important targets for research. While knocking out CHIP has been shown to exacerbate polyglutamine pathology (Williams et al., 2009), CHIP over-expression can reduce proteotoxicity and the effects of cellular stress in numerous models (Miller et al., 2005; Adachi et al., 2007; Lee et al., 2013). But CHIP induction without concurrent upregulation of Hsp70 might worsen tau pathology, suggesting that combinatorial approaches to therapy will be required.

In considering the specific goals and appropriate timing for interventions intended to prevent or delay disease onset, it is important to acknowledge that the loss of synapses can precede neurodegeneration and is thought to underlie many of the earliest cognitive impairments in numerous diseases. As such, it may represent a key step in the disease cascade and a critically important target for therapies. Alternatively, synaptic connections may simply be too costly for unhealthy neurons to properly maintain, and the loss of synaptic connections is, in effect, a response intended to limit inappropriate and potentially dangerous synaptic signaling in disease states. In the latter case, this dauer-like state is ultimately ineffective in staving off neurodegeneration, but may slow the process. With respect to human disease, perhaps restoring synapses could improve quality of life-regardless of whether such a change ultimately lengthens or shortens the life-span of affected neurons. For this reason, elucidation of the processes by which ubiquitin governs synapse formation, maintenance, and removal under normal conditions may prove invaluable.

\section{REFERENCES}

Abou-Sleiman, P. M., Healy, D. G., Quinn, N., Lees, A. J., and Wood, N. W. (2003). The role of pathogenic DJ-1 mutations in Parkinson's disease. Ann. Neurol. 54, 283-286. doi: 10.1002/ana.10675

Adachi, H., Waza, M., Tokui, K., Katsuno, M., Minamiyama, M., Tanaka, F., et al. (2007). CHIP overexpression reduces mutant androgen receptor protein and ameliorates phenotypes of the spinal and bulbar muscular atrophy transgenic 
mouse model. J. Neurosci. 27, 5115-5126. doi: 10.1523/JNEUROSCI.124207.2007

Alves-Rodrigues, A., Gregori, L., and Figueiredo-Pereira, M. E. (1998). Ubiquitin, cellular inclusions and their role in neurodegeneration. Trends Neurosci. 21, 516-520. doi: 10.1016/S0166-2236(98)01276-4

Andersen, P. M., and Al-Chalabi, A. (2011). Clinical genetics of amyotrophic lateral sclerosis: what do we really know? Nat. Rev. Neurol. 7, 603-615. doi: 10.1038/nrneurol.2011.150

Ardley, H. C., and Robinson, P. A. (2005). E3 ubiquitin ligases. Essays Biochem. 41, 15-30. doi: 10.1042/EB0410015

Ash, P. E., Bieniek, K. F., Gendron, T. F., Caulfield, T., Lin, W. L., DejesusHernandez, M., et al. (2013). Unconventional translation of C9ORF72 GGGGCC expansion generates insoluble polypeptides specific to c9FTD/ALS. Neuron 77, 639-646. doi: 10.1016/j.neuron.2013.02.004

Atkin, G., Hunt, J., Minakawa, E., Sharkey, L., Tipper, N., Tennant, W., et al. (2014). F-box only protein 2 (Fbxo2) regulates amyloid precursor levels and processing. J. Biol. Chem. 289, 7038-7048. doi: 10.1074/jbc.M113.515056

Azevedo, F. A., Carvalho, L. R., Grinberg, L. T., Farfel, J. M., Ferretti, R. E., Leite, R. E., et al. (2009). Equal numbers of neuronal and nonneuronal cells make the human brain an isometrically scaled-up primate brain. J. Comp. Neurol. 513, 532-541. doi: 10.1002/cne.21974

Bajic, N., Jenner, P., Ballard, C. G., and Francis, P. T. (2012). Proteasome inhibition leads to early loss of synaptic proteins in neuronal culture. J. Neural Transm. 119, 1467-1476. doi: 10.1007/s00702-012-0816-9

Bence, N. F., Sampat, R. M., and Kopito, R. R. (2001). Impairment of the ubiquitin-proteasome system by protein aggregation. Science 292, 1552-1555. doi: $10.1126 /$ science.292.5521.1552

Ben-Neriah, Y. (2002). Regulatory functions of ubiquitination in the immune system. Nat. Immunol. 3, 20-26. doi: 10.1038/ni0102-20

Bernassola, F., Ciechanover, A., and Melino, G. (2010). The ubiquitin proteasome system and its involvement in cell death pathways. Cell Death Differ. 17, 1-3. doi: $10.1038 /$ cdd.2009.189

Bertram, L., Lill, C. M., and Tanzi, R. E. (2010). The genetics of Alzheimer disease: back to the future. Neuron 68, 270-281. doi: 10.1016/j.neuron.2010.10.013

Bertrand, M. J., Lippens, S., Staes, A., Gilbert, B., Roelandt, R., De Medts, J., et al. (2011). cIAP1/2 are direct E3 ligases conjugating diverse types of ubiquitin chains to receptor interacting proteins kinases 1 to 4 (RIP1-4). PLoS ONE 6:e22356. doi: 10.1371/journal.pone.0022356

Biggs, J. R., Peterson, L. F., Zhang, Y., Kraft, A. S., and Zhang, D. E. (2006). AML1/RUNX1 phosphorylation by cyclin-dependent kinases regulates the degradation of AML1/RUNX1 by the anaphase-promoting complex. Mol. Cell. Biol. 26, 7420-7429. doi: 10.1128/MCB.00597-06

Bingol, B., and Schuman, E. M. (2004). A proteasome-sensitive connection between PSD-95 and GluR1 endocytosis. Neuropharmacology 47, 755-763. doi: 10.1016/j.neuropharm.2004.07.028

Bingol, B., and Schuman, E. M. (2005). Synaptic protein degradation by the ubiquitin proteasome system. Curr. Opin. Neurobiol. 15, 536-541. doi: 10.1016/j.conb.2005.08.016

Bingol, B., and Schuman, E. M. (2006). Activity-dependent dynamics and sequestration of proteasomes in dendritic spines. Nature 441, 1144-1148. doi: 10.1038 /nature04769

Bingol, B., and Sheng, M. (2011). Deconstruction for reconstruction: the role of proteolysis in neural plasticity and disease. Neuron 69, 22-32. doi: 10.1016/j.neuron.2010.11.006

Bingol, B., Wang, C. F., Arnott, D., Cheng, D., Peng, J., and Sheng, M. (2010). Autophosphorylated CaMKIIalpha acts as a scaffold to recruit proteasomes to dendritic spines. Cell 140, 567-578. doi: 10.1016/j.cell.2010.01.024

Boeve, B. F., Boylan, K. B., Graff-Radford, N. R., DeJesus-Hernandez, M., Knopman, D. S., Pedraza, O., et al. (2012). Characterization of frontotemporal dementia and/or amyotrophic lateral sclerosis associated with the GGGGCC repeat expansion in C9ORF72. Brain 135(Pt 3), 765-783. doi: 10.1093/brain/aws004

Borodovsky, A., Kessler, B. M., Casagrande, R., Overkleeft, H. S., Wilkinson, K. D., and Ploegh, H. L. (2001). A novel active site-directed probe specific for deubiquitylating enzymes reveals proteasome association of USP14. EMBO J. 20, 5187-5196. doi: 10.1093/emboj/20.18.5187

Bredesen, D. E. (2009). Neurodegeneration in Alzheimer's disease: caspases and synaptic element interdependence. Mol. Neurodegener. 4, 27. doi: 10.1186/1750$1326-4-27$
Buratti, E., and Baralle, F. E. (2001). Characterization and functional implications of the RNA binding properties of nuclear factor TDP-43, a novel splicing regulator of CFTR exon 9. J. Biol. Chem. 276, 36337-36343. doi: 10.1074/jbc.M104236200

Buratti, E., and Baralle, F. E. (2010). The multiple roles of TDP-43 in premRNA processing and gene expression regulation. RNA Biol. 7, 420-429. doi: 10.4161/rna.7.4.12205

Buschmann, T., Fuchs, S. Y., Lee, C. G., Pan, Z. Q., and Ronai, Z. (2000). SUMO-1 modification of Mdm2 prevents its self-ubiquitination and increases Mdm2 ability to ubiquitinate p53. Cell 101, 753-762. doi: 10.1016/S00928674(00)80887-9

Cano, F., Miranda-Saavedra, D., and Lehner, P. J. (2010). RNA-binding E3 ubiquitin ligases: novel players in nucleic acid regulation. Biochem. Soc. Trans. 38, 1621-1626. doi: 10.1042/BST0381621

Cardozo, T., and Pagano, M. (2004). The SCF ubiquitin ligase: insights into a molecular machine. Nat. Rev. Mol. Cell Biol. 5, 739-751. doi: 10.1038/nrm1471

Cartier, A. E., Ubhi, K., Spencer, B., Vazquez-Roque, R. A., Kosberg, K. A., Fourgeaud, L., et al. (2012). Differential effects of UCHL1 modulation on alphasynuclein in PD-like models of alpha-synucleinopathy. PLoS ONE 7:e34713. doi: 10.1371/journal.pone.0034713

Cattaneo, E., Zuccato, C., and Tartari, M. (2005). Normal Huntingtin function: an alternative approach to Huntington's disease. Nat. Rev. Neurosci. 6, 919-930. doi: 10.1038/nrn1806

Chen, Y., Neve, R. L., and Liu, H. (2012). Neddylation dysfunction in Alzheimer's disease. J. Cell. Mol. Med. 16, 2583-2591. doi: 10.1111/j.1582-4934.2012.01604.x

Chio, A., Borghero, G., Restagno, G., Mora, G., Drepper, C., Traynor, B. J., et al. (2012). Clinical characteristics of patients with familial amyotrophic lateral sclerosis carrying the pathogenic GGGGCC hexanucleotide repeat expansion of C9ORF72. Brain 135(Pt 3), 784-793. doi: 10.1093/brain/awr366

Choi, Y. E., Butterworth, M., Malladi, S., Duckett, C. S., Cohen, G. M., and Bratton, S. B. (2009). The E3 ubiquitin ligase cIAP1 binds and ubiquitinates caspase-3 and -7 via unique mechanisms at distinct steps in their processing. J. Biol. Chem. 284, 12772-12782. doi: 10.1074/jbc.M807550200

Chong, S. S., Almqvist, E., Telenius, H., LaTray, L., Nichol, K., Bourdelat-Parks, B., et al. (1997). Contribution of DNA sequence and CAG size to mutation frequencies of intermediate alleles for Huntington disease: evidence from single sperm analyses. Hum. Mol. Genet. 6, 301-309. doi: 10.1093/hmg/6.2.301

Choo, Y. S., Johnson, G. V., MacDonald, M., Detloff, P. J., and Lesort, M. (2004). Mutant Huntingtin directly increases susceptibility of mitochondria to the calcium-induced permeability transition and cytochrome c release. Hum. Mol. Genet. 13, 1407-1420. doi: 10.1093/hmg/ddh162

Colledge, M., Snyder, E. M., Crozier, R. A., Soderling, J. A., Jin, Y., Langeberg, L. K., et al. (2003). Ubiquitination regulates PSD-95 degradation and AMPA receptor surface expression. Neuron 40, 595-607. doi: 10.1016/S0896-6273(03)00687-1

Costa-Mattioli, M., and Monteggia, L. M. (2013). mTOR complexes in neurodevelopmental and neuropsychiatric disorders. Nat. Neurosci. 16, 1537-1543. doi: 10.1038/nn.3546

Dai, R. M., and Li, C. C. (2001). Valosin-containing protein is a multi-ubiquitin chain-targeting factor required in ubiquitin-proteasome degradation. Nat. Cell Biol. 3, 740-744. doi: 10.1038/35087056

D’Amelio, M., Cavallucci, V., Middei, S., Marchetti, C., Pacioni, S., Ferri, A., et al. (2011). Caspase-3 triggers early synaptic dysfunction in a mouse model of Alzheimer's disease. Nat. Neurosci. 14, 69-76. doi: 10.1038/nn.2709

Das, C., Hoang, Q. Q., Kreinbring, C. A., Luchansky, S. J., Meray, R. K., Ray, S. S., et al. (2006). Structural basis for conformational plasticity of the Parkinson's disease-associated ubiquitin hydrolase UCH-L1. Proc. Natl. Acad. Sci. U.S.A. 103, 4675-4680. doi: 10.1073/pnas.0510403103

de Pril, R., Fischer, D. F., Roos, R. A., and van Leeuwen, F. W. (2007). Ubiquitin-conjugating enzyme E2-25K increases aggregate formation and cell death in polyglutamine diseases. Mol. Cell. Neurosci. 34, 10-19. doi: 10.1016/j.mcn.2006.09.006

Dickey, C. A., Yue, M., Lin, W. L., Dickson, D. W., Dunmore, J. H., Lee, W. C., et al. (2006). Deletion of the ubiquitin ligase CHIP leads to the accumulation, but not the aggregation, of both endogenous phospho- and caspase-3-cleaved tau species. J. Neurosci. 26, 6985-6996. doi: 10.1523/JNEUROSCI.0746-06.2006

DiFiglia, M., Sapp, E., Chase, K. O., Davies, S. W., Bates, G. P., Vonsattel, J. P., et al. (1997). Aggregation of Huntingtin in neuronal intranuclear inclusions and dystrophic neurites in brain. Science 277, 1990-1993. doi: 10.1126/science.277.5334.1990 
Dil Kuazi, A., Kito, K., Abe, Y., Shin, R. W., Kamitani, T., and Ueda, N. (2003). NEDD8 protein is involved in ubiquitinated inclusion bodies. J. Pathol. 199, 259-266. doi: 10.1002/path.1283

Dreier, L., Burbea, M., and Kaplan, J. M. (2005). LIN-23-mediated degradation of beta-catenin regulates the abundance of GLR-1 glutamate receptors in the ventral nerve cord of C. elegans. Neuron 46, 51-64. doi: 10.1016/j.neuron.2004.12.058

Duda, D. M., Borg, L. A., Scott, D. C., Hunt, H. W., Hammel, M., and Schulman, B. A. (2008). Structural insights into NEDD8 activation of cullinRING ligases: conformational control of conjugation. Cell 134, 995-1006. doi: 10.1016/j.cell.2008.07.022

Ehlers, M. D. (2003). Activity level controls postsynaptic composition and signaling via the ubiquitin-proteasome system. Nat. Neurosci. 6, 231-242. doi: 10.1038/nn1013

El Ayadi, A., Stieren, E. S., Barral, J. M., and Boehning, D. (2012). Ubiquilin-1 regulates amyloid precursor protein maturation and degradation by stimulating K63-linked polyubiquitination of lysine 688. Proc. Natl. Acad. Sci. U.S.A. 109, 13416-13421. doi: 10.1073/pnas.1206786109

Fallon, L., Belanger, C. M., Corera, A. T., Kontogiannea, M., Regan-Klapisz, E., Moreau, F., et al. (2006). A regulated interaction with the UIM protein Eps15 implicates parkin in EGF receptor trafficking and PI(3)K-Akt signalling. Nat. Cell Biol. 8, 834-842. doi: 10.1038/ncb1441

Finley, D. (2009). Recognition and processing of ubiquitin-protein conjugates by the proteasome. Annu. Rev. Biochem. 78, 477-513. doi: 10.1146/annurev.biochem.78.081507.101607

Finley, D., and Chau, V. (1991). Ubiquitination. Annu. Rev. Cell Biol. 7, 25-69. doi: 10.1146/annurev.cb.07.110191.000325

Fu, A. K., Hung, K. W., Fu, W. Y., Shen, C., Chen, Y., Xia, J., et al. (2011). APC(Cdh1) mediates EphA4-dependent downregulation of AMPA receptors in homeostatic plasticity. Nat. Neurosci. 14, 181-189. doi: 10.1038/ nn. 2715

Garcia-Arencibia, M., Hochfeld, W. E., Toh, P. P., and Rubinsztein, D. C. (2010). Autophagy, a guardian against neurodegeneration. Semin. Cell Dev. Biol. 21, 691-698. doi: 10.1016/j.semcdb.2010.02.008

Ghosh, P., Wu, M., Zhang, H., and Sun, H. (2008). mTORC1 signaling requires proteasomal function and the involvement of CUL4-DDB1 ubiquitin E3 ligase. Cell Cycle 7, 373-381. doi: 10.4161/cc.7.3.5267

Gitcho, M. A., Baloh, R. H., Chakraverty, S., Mayo, K., Norton, J. B., Levitch, D., et al. (2008). TDP-43 A315T mutation in familial motor neuron disease. Ann. Neurol. 63, 535-538. doi: 10.1002/ana.21344

Gladding, C. M., Sepers, M. D., Xu, J., Zhang, L. Y., Milnerwood, A. J., Lombroso, P. J., et al. (2012). Calpain and STriatal-Enriched protein tyrosine phosphatase (STEP) activation contribute to extrasynaptic NMDA receptor localization in a Huntington's disease mouse model. Hum. Mol. Genet. 21, 3739-3752. doi: $10.1093 / \mathrm{hmg} / \mathrm{dds} 154$

Glenner, G. G., Wong, C. W., Quaranta, V., and Eanes, E. D. (1984). The amyloid deposits in Alzheimer's disease: their nature and pathogenesis. Appl. Pathol. 2, 357-369.

Glickman, M. H., and Ciechanover, A. (2002). The ubiquitin-proteasome proteolytic pathway: destruction for the sake of construction. Physiol. Rev. 82, 373-428. doi: 10.1152/physrev.00027.2001

Goedert, M., Wischik, C. M., Crowther, R. A., Walker, J. E., and Klug, A. (1988). Cloning and sequencing of the cDNA encoding a core protein of the paired helical filament of Alzheimer disease: identification as the microtubuleassociated protein tau. Proc. Natl. Acad. Sci. U.S.A. 85, 4051-4055. doi: 10.1073/pnas.85.11.4051

Golgi, C. (1886). Sulla Fina Anatomia degli Organi Centrali del Sistema Nervoso. Milane: U. Hoepli.

Gong, B., Chen, F., Pan, Y., Arrieta-Cruz, I., Yoshida, Y., Haroutunian, V., et al. (2010). SCFFbx2-E3-ligase-mediated degradation of BACE1 attenuates Alzheimer's disease amyloidosis and improves synaptic function. Aging Cell 9, 1018-1031. doi: 10.1111/j.1474-9726.2010.00632.x

Greene, J. C., Whitworth, A. J., Kuo, I., Andrews, L. A., Feany, M. B., and Pallanck, L. J. (2003). Mitochondrial pathology and apoptotic muscle degeneration in Drosophila parkin mutants. Proc. Natl. Acad. Sci. U.S.A. 100, 4078-4083. doi: 10.1073/pnas.0737556100

Hadari, T., Warms, J. V., Rose, I. A., and Hershko, A. (1992). A ubiquitin C-terminal isopeptidase that acts on polyubiquitin chains. Role in protein degradation. J. Biol. Chem. 267, 719-727.
Hadian, K., Griesbach, R. A., Dornauer, S., Wanger, T. M., Nagel, D., Metlitzky, M., et al. (2011). NF-kappaB essential modulator (NEMO) interaction with linear and lys-63 ubiquitin chains contributes to NF-kappaB activation. J. Biol. Chem. 286, 26107-26117. doi: 10.1074/jbc.M111.233163

Haglund, K., Di Fiore, P. P., and Dikic, I. (2003). Distinct monoubiquitin signals in receptor endocytosis. Trends Biochem. Sci. 28, 598-603. doi: 10.1016/j.tibs.2003.09.005

Hanus, C., and Schuman, E. M. (2013). Proteostasis in complex dendrites. Nat. Rev. Neurosci. 14, 638-648. doi: 10.1038/nrn3546

Hao, B., Zheng, N., Schulman, B. A., Wu, G., Miller, J. J., Pagano, M., et al. (2005). Structural basis of the Cks1-dependent recognition of p27(Kip1) by the SCF(Skp2) ubiquitin ligase. Mol. Cell 20, 9-19. doi: 10.1016/j.molcel.2005.09.003

Hardingham, G. E., and Bading, H. (2010). Synaptic versus extrasynaptic NMDA receptor signalling: implications for neurodegenerative disorders. Nat. Rev. Neurosci. 11, 682-696. doi: 10.1038/nrn2911

Hardy, J. (2003). Impact of genetic analysis on Parkinson's disease research. Mov. Disord. 18(Suppl. 6), S96-S98. doi: 10.1002/mds.10569

Hay, N., and Sonenberg, N. (2004). Upstream and downstream of mTOR. Genes Dev. 18, 1926-1945. doi: 10.1101/gad.1212704

Hebron, M. L., Lonskaya, I., Sharpe, K., Weerasinghe, P. P., Algarzae, N. K., Shekoyan, A. R., et al. (2013). Parkin ubiquitinates Tar-DNA binding protein-43 (TDP-43) and promotes its cytosolic accumulation via interaction with histone deacetylase 6 (HDAC6). J. Biol. Chem. 288, 4103-4115. doi: 10.1074/jbc.M112.419945

Hegde, A. N., Broome, B. M., Qiang, M., and Schwartz, J. H. (2000). Structure and expression of the Aplysia polyubiquitin gene. Brain Res. Mol. Brain Res. 76, 424-428. doi: 10.1016/S0169-328X(00)00021-8

Hegde, A. N., Inokuchi, K., Pei, W., Casadio, A., Ghirardi, M., Chain, D. G., et al. (1997). Ubiquitin C-terminal hydrolase is an immediate-early gene essential for long-term facilitation in Aplysia. Cell 89, 115-126. doi: 10.1016/S00928674(00)80188-9

Hegde, A. N., and Upadhya, S. C. (2007). The ubiquitin-proteasome pathway in health and disease of the nervous system. Trends Neurosci. 30, 587-595. doi: 10.1016/j.tins.2007.08.005

Herculano-Houzel, S. (2011). Scaling of brain metabolism with a fixed energy budget per neuron: implications for neuronal activity, plasticity and evolution. PLoS ONE 6:e17514. doi: 10.1371/journal.pone.0017514

Hernandez, F., Gomez de Barreda, E., Fuster-Matanzo, A., Lucas, J. J., and Avila, J. (2010). GSK3: a possible link between beta amyloid peptide and tau protein. Exp. Neurol. 223, 322-325. doi: 10.1016/j.expneurol.2009.09.011

Hershko, A., and Ciechanover, A. (1998). The ubiquitin system. Annu. Rev. Biochem. 67, 425-479. doi: 10.1146/annurev.biochem.67.1.425

Hicke, L., and Dunn, R. (2003). Regulation of membrane protein transport by ubiquitin and ubiquitin-binding proteins. Annu. Rev. Cell Dev. Biol. 19, 141-172. doi: 10.1146/annurev.cellbio.19.110701.154617

Hochfeld, W. E., Lee, S., and Rubinsztein, D. C. (2013). Therapeutic induction of autophagy to modulate neurodegenerative disease progression. Acta Pharmacol. Sin. 34, 600-604. doi: 10.1038/aps.2012.189

Hoeffer, C. A., and Klann, E. (2010). mTOR signaling: at the crossroads of plasticity, memory and disease. Trends Neurosci. 33, 67-75. doi: 10.1016/j.tins.2009.11.003

Hoege, C., Pfander, B., Moldovan, G. L., Pyrowolakis, G., and Jentsch, S. (2002). RAD6-dependent DNA repair is linked to modification of PCNA by ubiquitin and SUMO. Nature 419, 135-141. doi: 10.1038/nature00991

Holmberg, C. I., Staniszewski, K. E., Mensah, K. N., Matouschek, A., and Morimoto, R. I. (2004). Inefficient degradation of truncated polyglutamine proteins by the proteasome. EMBO J. 23, 4307-4318. doi: 10.1038/sj.emboj.7600426

Hong, X., Liu, J., Zhu, G., Zhuang, Y., Suo, H., Wang, P., et al. (2014). Parkin overexpression ameliorates hippocampal long-term potentiation and beta-amyloid load in an Alzheimer's disease mouse model. Hum. Mol. Genet. 23, 1056-1072. doi: $10.1093 / \mathrm{hmg} / \mathrm{ddt} 501$

Hough, R., Pratt, G., and Rechsteiner, M. (1987). Purification of two high molecular weight proteases from rabbit reticulocyte lysate. J. Biol. Chem. 262, 8303-8313.

Huang, F., Zeng, X., Kim, W., Balasubramani, M., Fortian, A., Gygi, S. P., et al. (2013). Lysine 63-linked polyubiquitination is required for EGF receptor degradation. Proc. Natl. Acad. Sci. U.S.A. 110, 15722-15727. doi: 10.1073/pnas. 1308014110 
Huang, Q., and Figueiredo-Pereira, M. E. (2010). Ubiquitin/proteasome pathway impairment in neurodegeneration: therapeutic implications. Apoptosis 15, 1292-1311. doi: 10.1007/s10495-010-0466-Z

Huibregtse, J. M., Scheffner, M., Beaudenon, S., and Howley, P. M. (1995). A family of proteins structurally and functionally related to the E6-AP ubiquitin-protein ligase. Proc. Natl. Acad. Sci. U.S.A. 92, 2563-2567. doi: 10.1073/pnas.92.7.2563

Hung, A. Y., Sung, C. C., Brito, I. L., and Sheng, M. (2010). Degradation of postsynaptic scaffold GKAP and regulation of dendritic spine morphology by the TRIM3 ubiquitin ligase in rat hippocampal neurons. PLoS ONE 5:e9842. doi: 10.1371/journal.pone.0009842

Husnjak, K., and Dikic, I. (2012). Ubiquitin-binding proteins: decoders of ubiquitin-mediated cellular functions. Annu. Rev. Biochem. 81, 291-322. doi: 10.1146/annurev-biochem-051810-094654

Hussain, S., Feldman, A. L., Das, C., Ziesmer, S. C., Ansell, S. M., and Galardy, P. J. (2013). Ubiquitin hydrolase UCH-L1 destabilizes mTOR complex 1 by antagonizing DDB1-CUL4-mediated ubiquitination of raptor. Mol. Cell. Biol. 33, 1188-1197. doi: 10.1128/MCB.01389-12

Igaz, L. M., Kwong, L. K., Lee, E. B., Chen-Plotkin, A., Swanson, E., Unger, T., et al. (2011). Dysregulation of the ALS-associated gene TDP-43 leads to neuronal death and degeneration in mice. J. Clin. Invest. 121, 726-738. doi: 10.1172/JCI44867

Ikeda, F., and Dikic, I. (2008). Atypical ubiquitin chains: new molecular signals. 'Protein Modifications: beyond the Usual Suspects' review series. EMBO Rep. 9, 536-542. doi: 10.1038/embor.2008.93

Imai, Y., Soda, M., Hatakeyama, S., Akagi, T., Hashikawa, T., Nakayama, K. I., et al. (2002). CHIP is associated with Parkin, a gene responsible for familial Parkinson's disease, and enhances its ubiquitin ligase activity. Mol. Cell 10, 55-67. doi: 10.1016/S1097-2765(02)00583-X

Iwakura, Y., Piao, Y. S., Mizuno, M., Takei, N., Kakita, A., Takahashi, H., et al. (2005). Influences of dopaminergic lesion on epidermal growth factor-ErbB signals in Parkinson's disease and its model: neurotrophic implication in nigrostriatal neurons. J. Neurochem. 93, 974-983. doi: 10.1111/j.1471-4159.2005.03073.x

Jackson, S. P., and Durocher, D. (2013). Regulation of DNA damage responses by ubiquitin and SUMO. Mol. Cell 49, 795-807. doi: 10.1016/j.molcel.2013.01.017

Jacobson, A. D., Zhang, N. Y., Xu, P., Han, K. J., Noone, S., Peng, J., et al. (2009). The lysine 48 and lysine 63 ubiquitin conjugates are processed differently by the $26 \mathrm{~s}$ proteasome. J. Biol. Chem. 284, 35485-35494. doi: 10.1074/jbc.M109.052928

Janssens, J., and Van Broeckhoven, C. (2013). Pathological mechanisms underlying TDP-43 driven neurodegeneration in FTLD-ALS spectrum disorders. Hum. Mol. Genet. 22, R77-R87. doi: 10.1093/hmg/ddt349

Jia, H., Kast, R. J., Steffan, J. S., and Thomas, E. A. (2012). Selective histone deacetylase (HDAC) inhibition imparts beneficial effects in Huntington's disease mice: implications for the ubiquitin-proteasomal and autophagy systems. Hum. Mol. Genet. 21, 5280-5293. doi: 10.1093/hmg/dds379

Jurd, R., Thornton, C., Wang, J., Luong, K., Phamluong, K., Kharazia, V., et al. (2008). Mind bomb-2 is an E3 ligase that ubiquitinates the N-methyl-Daspartate receptor NR2B subunit in a phosphorylation-dependent manner. J. Biol. Chem. 283, 301-310. doi: 10.1074/jbc.M705580200

Kalchman, M. A., Graham, R. K., Xia, G., Koide, H. B., Hodgson, J. G., Graham, K. C., et al. (1996). Huntingtin is ubiquitinated and interacts with a specific ubiquitin-conjugating enzyme. J. Biol. Chem. 271, 19385-19394. doi: 10.1074/jbc.271.32.19385

Kamitani, T., Kito, K., Fukuda-Kamitani, T., and Yeh, E. T. (2001). Targeting of NEDD8 and its conjugates for proteasomal degradation by NUB1. J. Biol. Chem. 276, 46655-46660. doi: 10.1074/jbc.M108636200

Kaneko, M., Koike, H., Saito, R., Kitamura, Y., Okuma, Y., and Nomura, Y. (2010). Loss of HRD1-mediated protein degradation causes amyloid precursor protein accumulation and amyloid-beta generation. J. Neurosci. 30, 3924-3932. doi: 10.1523/JNEUROSCI.2422-09.2010

Kato, A., Rouach, N., Nicoll, R. A., and Bredt, D. S. (2005). Activitydependent NMDA receptor degradation mediated by retrotranslocation and ubiquitination. Proc. Natl. Acad. Sci. U.S.A. 102, 5600-5605. doi: 10.1073/pnas.0501769102

Keller, J. N., Hanni, K. B., and Markesbery, W. R. (2000). Impaired proteasome function in Alzheimer's disease. J. Neurochem. 75, 436-439. doi: 10.1046/j.14714159.2000.0750436.x

Khan, N. L., Graham, E., Critchley, P., Schrag, A. E., Wood, N. W., Lees, A. J., et al. (2003). Parkin disease: a phenotypic study of a large case series. Brain 126(Pt 6), 1279-1292. doi: 10.1093/brain/awg142
Kito, K., Yeh, E. T., and Kamitani, T. (2001). NUB1, a NEDD8-interacting protein, is induced by interferon and down-regulates the NEDD8 expression. J. Biol. Chem. 276, 20603-20609. doi: 10.1074/jbc.M100920200

Kruger, R., Kuhn, W., Muller, T., Woitalla, D., Graeber, M., Kosel, S., et al. (1998). Ala30Pro mutation in the gene encoding alpha-synuclein in Parkinson's disease. Nat. Genet. 18, 106-108. doi: 10.1038/ng0298-106

Kumar, P., Ambasta, R. K., Veereshwarayya, V., Rosen, K. M., Kosik, K. S., Band, H., et al. (2007). CHIP and HSPs interact with beta-APP in a proteasomedependent manner and influence Abeta metabolism. Hum. Mol. Genet. 16, 848-864. doi: 10.1093/hmg/ddm030

Kumar, S., Yoshida, Y., and Noda, M. (1993). Cloning of a cDNA which encodes a novel ubiquitin-like protein. Biochem. Biophys. Res. Commun. 195, 393-399. doi: 10.1006/bbrc.1993.2056

Kunst, C. B., Mezey, E., Brownstein, M. J., and Patterson, D. (1997). Mutations in SOD1 associated with amyotrophic lateral sclerosis cause novel protein interactions. Nat. Genet. 15, 91-94. doi: 10.1038/ng0197-91

Laaksovirta, H., Peuralinna, T., Schymick, J. C., Scholz, S. W., Lai, S. L., Myllykangas, L., et al. (2010). Chromosome 9p21 in amyotrophic lateral sclerosis in Finland: a genome-wide association study. Lancet Neurol. 9, 978-985. doi: 10.1016/S1474-4422(10)70184-8

Lee, J. S., Seo, T. W., Yi, J. H., Shin, K. S., and Yoo, S. J. (2013). CHIP has a protective role against oxidative stress-induced cell death through specific regulation of endonuclease G. Cell Death Dis. 4, e666. doi: 10.1038/cddis.2013.181

Lee, M. C., Yasuda, R., and Ehlers, M. D. (2010). Metaplasticity at single glutamatergic synapses. Neuron 66, 859-870. doi: 10.1016/j.neuron.2010.05.015

Lee, S. J., Choi, J. Y., Sung, Y. M., Park, H., Rhim, H., and Kang, S. (2001). E3 ligase activity of RING finger proteins that interact with Hip-2, a human ubiquitin-conjugating enzyme. FEBS Lett. 503, 61-64. doi: 10.1016/S00145793(01)02689-8

Li, J., Pauley, A. M., Myers, R. L., Shuang, R., Brashler, J. R., Yan, R., et al. (2002). SEL-10 interacts with presenilin 1, facilitates its ubiquitination, and alters A-beta peptide production. J. Neurochem. 82, 1540-1548. doi: 10.1046/j.14714159.2002.01105.x

Lindersson, E., Beedholm, R., Hojrup, P., Moos, T., Gai, W., Hendil, K. B., et al. (2004). Proteasomal inhibition by alpha-synuclein filaments and oligomers. J. Biol. Chem. 279, 12924-12934. doi: 10.1074/jbc.M306390200

Liu, Y., Fallon, L., Lashuel, H. A., Liu, Z., and Lansbury, P. T. Jr. (2002). The UCH-L1 gene encodes two opposing enzymatic activities that affect alphasynuclein degradation and Parkinson's disease susceptibility. Cell 111, 209-218. doi: 10.1016/S0092-8674(02)01012-7

Lonskaya, I., Desforges, N. M., Hebron, M. L., and Moussa, C. E. (2013). Ubiquitination increases parkin activity to promote autophagic alpha-synuclein clearance. PLoS ONE 8:e83914. doi: 10.1371/journal.pone.0083914

Lorick, K. L., Jensen, J. P., Fang, S., Ong, A. M., Hatakeyama, S., and Weissman, A. M. (1999). RING fingers mediate ubiquitin-conjugating enzyme (E2)dependent ubiquitination. Proc. Natl. Acad. Sci. U.S.A. 96, 11364-11369. doi: 10.1073/pnas.96.20.11364

Lowe, J. (1994). New pathological findings in amyotrophic lateral sclerosis. J. Neurol. Sci. 124(Suppl.), 38-51. doi: 10.1016/0022-510X(94)90175-9

Lowe, J., Stock, D., Jap, B., Zwickl, P., Baumeister, W., and Huber, R. (1995). Crystal structure of the $20 \mathrm{~S}$ proteasome from the archaeon T. acidophilum at $3.4 \mathrm{~A}$ resolution. Science 268, 533-539. doi: 10.1126/science.7725097

Lu, B., Al-Ramahi, I., Valencia, A., Wang, Q., Berenshteyn, F., Yang, H., et al. (2013). Identification of NUB1 as a suppressor of mutant Huntington toxicity via enhanced protein clearance. Nat. Neurosci. 16, 562-570. doi: 10.1038/ nn.3367

Lu, X. H., Fleming, S. M., Meurers, B., Ackerson, L. C., Mortazavi, F., Lo, V., et al. (2009). Bacterial artificial chromosome transgenic mice expressing a truncated mutant parkin exhibit age-dependent hypokinetic motor deficits, dopaminergic neuron degeneration, and accumulation of proteinase K-resistant alpha-synuclein. J. Neurosci. 29, 1962-1976. doi: 10.1523/JNEUROSCI.535108.2009

Lucking, C. B., Durr, A., Bonifati, V., Vaughan, J., De Michele, G., Gasser, T., et al. (2000). Association between early-onset Parkinson's disease and mutations in the parkin gene. N. Engl. J. Med. 342, 1560-1567. doi: 10.1056/NEJM200005253422103

Lussier, M. P., Nasu-Nishimura, Y., and Roche, K. W. (2011). Activity-dependent ubiquitination of the AMPA receptor subunit GluA2. J. Neurosci. 31, 3077-3081. doi: 10.1523/JNEUROSCI.5944-10.2011 
Mackenzie, I. R., Frick, P., and Neumann, M. (2014). The neuropathology associated with repeat expansions in the C9ORF72 gene. Acta Neuropathol. 127, 347-357. doi: 10.1007/s00401-013-1232-4

Maestre, C., Delgado-Esteban, M., Gomez-Sanchez, J. C., Bolanos, J. P., and Almeida, A. (2008). Cdk5 phosphorylates Cdh1 and modulates cyclin B1 stability in excitotoxicity. EMBO J. 27, 2736-2745. doi: 10.1038/emboj. 2008.195

Marland, J. R., Pan, D., and Buttery, P. C. (2011). Rac GTPase-activating protein (Rac GAP) alpha1-Chimaerin undergoes proteasomal degradation and is stabilized by diacylglycerol signaling in neurons. J. Biol. Chem. 286, 199-207. doi: 10.1074/jbc.M110.166728

Masliah, E., Hansen, L., Albright, T., Mallory, M., and Terry, R. D. (1991a). Immunoelectron microscopic study of synaptic pathology in Alzheimer's disease. Acta Neuropathol. 81, 428-433. doi: 10.1007/BF00293464

Masliah, E., Terry, R. D., Alford, M., DeTeresa, R., and Hansen, L. A. (1991b). Cortical and subcortical patterns of synaptophysinlike immunoreactivity in Alzheimer's disease. Am. J. Pathol. 138, 235-246.

Matsumoto, M. L., Wickliffe, K. E., Dong, K. C., Yu, C., Bosanac, I., Bustos, D., et al. (2010). K11-linked polyubiquitination in cell cycle control revealed by a K11 linkage-specific antibody. Mol. Cell 39, 477-484. doi: 10.1016/j.molcel.2010.07.001

McNaught, K. S., Belizaire, R., Isacson, O., Jenner, P., and Olanow, C. W. (2003). Altered proteasomal function in sporadic Parkinson's disease. Exp. Neurol. 179, 38-46. doi: 10.1006/exnr.2002.8050

McNaught, K. S., Bjorklund, L. M., Belizaire, R., Isacson, O., Jenner, P., and Olanow, C. W. (2002). Proteasome inhibition causes nigral degeneration with inclusion bodies in rats. Neuroreport 13, 1437-1441. doi: 10.1097/00001756-20020807000018

McNaught, K. S., and Jenner, P. (2001). Proteasomal function is impaired in substantia nigra in Parkinson's disease. Neurosci. Lett. 297, 191-194. doi: 10.1016/S0304-3940(00)01701-8

McNaught, K. S., and Olanow, C. W. (2006). Proteasome inhibitor-induced model of Parkinson's disease. Ann. Neurol. 60, 243-247. doi: 10.1002/ana.20936

Mealer, R. G., Murray, A. J., Shahani, N., Subramaniam, S., and Snyder, S. H. (2013). Rhes, a striatal-selective protein implicated in Huntington disease, binds beclin-1 and activates autophagy. J. Biol. Chem. 289, 3547-3554. doi: 10.1074/ jbc.M113.536912

Mei, J., and Niu, C. (2010). Alterations of Hrdl expression in various encephalic regional neurons in 6-OHDA model of Parkinson's disease. Neurosci. Lett. 474, 63-68. doi: 10.1016/j.neulet.2010.02.033

Metcalf, D. J., Garcia-Arencibia, M., Hochfeld, W. E., and Rubinsztein, D. C. (2012). Autophagy and misfolded proteins in neurodegeneration. Exp. Neurol. 238, 22-28. doi: 10.1016/j.expneurol.2010.11.003

Miller, V. M., Nelson, R. F., Gouvion, C. M., Williams, A., Rodriguez-Lebron, E., Harper, S. Q., et al. (2005). CHIP suppresses polyglutamine aggregation and toxicity in vitro and in vivo. J. Neurosci. 25, 9152-9161. doi: 10.1523/JNEUROSCI.3001-05.2005

Milnerwood, A. J., Gladding, C. M., Pouladi, M. A., Kaufman, A. M., Hines, R. M., Boyd, J. D., et al. (2010). Early increase in extrasynaptic NMDA receptor signaling and expression contributes to phenotype onset in Huntington's disease mice. Neuron 65, 178-190. doi: 10.1016/j.neuron.2010.01.031

Mishra, A., Maheshwari, M., Chhangani, D., Fujimori-Tonou, N., Endo, F., Joshi, A. P., et al. (2013). E6-AP association promotes SOD1 aggresomes degradation and suppresses toxicity. Neurobiol. Aging 34, 1310.e11-1310.e23. doi: 10.1016/j.neurobiolaging.2012.08.016

Miyazaki, K., Fujita, T., Ozaki, T., Kato, C., Kurose, Y., Sakamoto, M., et al. (2004). NEDL1, a novel ubiquitin-protein isopeptide ligase for dishevelled-1, targets mutant superoxide dismutase-1. J. Biol. Chem. 279, 11327-11335. doi: 10.1074/jbc.M312389200

Moldovan, G. L., Pfander, B., and Jentsch, S. (2007). PCNA, the maestro of the replication fork. Cell 129, 665-679. doi: 10.1016/j.cell.2007.05.003

Mukhopadhyay, D., and Riezman, H. (2007). Proteasome-independent functions of ubiquitin in endocytosis and signaling. Science 315, 201-205. doi: 10.1126/science. 1127085

Myers, R. H., MacDonald, M. E., Koroshetz, W. J., Duyao, M. P., Ambrose, C. M., Taylor, S. A., et al. (1993). De novo expansion of a (CAG)n repeat in sporadic Huntington's disease. Nat. Genet. 5, 168-173. doi: 10.1038/ng1093-168

Nair, V. D., McNaught, K. S., Gonzalez-Maeso, J., Sealfon, S. C., and Olanow, C. W. (2006). p53 mediates nontranscriptional cell death in dopaminergic cells in response to proteasome inhibition. J. Biol. Chem. 281, 39550-39560. doi: 10.1074/jbc.M603950200

Nakamura, T., Tu, S., Akhtar, M. W., Sunico, C. R., Okamoto, S., and Lipton, S. A. (2013). Aberrant protein s-nitrosylation in neurodegenerative diseases. Neuron 78, 596-614. doi: 10.1016/j.neuron.2013.05.005

Nakamura, T., Wang, L., Wong, C. C., Scott, F. L., Eckelman, B. P., Han, X., et al. (2010). Transnitrosylation of XIAP regulates caspase-dependent neuronal cell death. Mol. Cell 39, 184-195. doi: 10.1016/j.molcel.2010.07.002

Neumann, M., Sampathu, D. M., Kwong, L. K., Truax, A. C., Micsenyi, M. C., Chou, T. T., et al. (2006). Ubiquitinated TDP-43 in frontotemporal lobar degeneration and amyotrophic lateral sclerosis. Science 314, 130-133. doi: 10.1126/science. 1134108

Niwa, J., Ishigaki, S., Hishikawa, N., Yamamoto, M., Doyu, M., Murata, S., et al. (2002). Dorfin ubiquitylates mutant SOD1 and prevents mutant SOD1-mediated neurotoxicity. J. Biol. Chem. 277, 36793-36798. doi: 10.1074/jbc.M206559200

Nixon, R. A. (2013). The role of autophagy in neurodegenerative disease. Nat. Med. 19, 983-997. doi: 10.1038/nm.3232

Okamoto, S., Pouladi, M. A., Talantova, M., Yao, D., Xia, P., Ehrnhoefer, D. E., et al. (2009). Balance between synaptic versus extrasynaptic NMDA receptor activity influences inclusions and neurotoxicity of mutant Huntingtin. Nat. Med. 15, 1407-1413. doi: 10.1038/nm.2056

Olzmann, J. A., and Chin, L. S. (2008). Parkin-mediated K63-linked polyubiquitination: a signal for targeting misfolded proteins to the aggresome-autophagy pathway. Autophagy 4, 85-87. doi: 10.1083/jcb.200611128

Orr, H. T. (2012). Polyglutamine neurodegeneration: expanded glutamines enhance native functions. Curr. Opin. Genet. Dev. 22, 251-255. doi: 10.1016/j.gde.2012.01.001

Pak, D. T., and Sheng, M. (2003). Targeted protein degradation and synapse remodeling by an inducible protein kinase. Science 302, 1368-1373. doi: 10.1126/science. 1082475

Parsons, M. P., Kang, R., Buren, C., Dau, A., Southwell, A. L., Doty, C. N., et al. (2013). Bidirectional control of postsynaptic density-95 (PSD-95) clustering by Huntingtin. J. Biol. Chem. doi: 10.1074/jbc.M113.513945

Patrick, G. N., Bingol, B., Weld, H. A., and Schuman, E. M. (2003). Ubiquitinmediated proteasome activity is required for agonist-induced endocytosis of GluRs. Curr. Biol. 13, 2073-2081. doi: 10.1016/j.cub.2003.10.028

Peng, J., Schwartz, D., Elias, J. E., Thoreen, C. C., Cheng, D., Marsischky, G., et al. (2003). A proteomics approach to understanding protein ubiquitination. Nat. Biotechnol. 21, 921-926. doi: 10.1038/nbt849

Peng, S., Wuu, J., Mufson, E. J., and Fahnestock, M. (2005). Precursor form of brain-derived neurotrophic factor and mature brain-derived neurotrophic factor are decreased in the pre-clinical stages of Alzheimer's disease. J. Neurochem. 93, 1412-1421. doi: 10.1111/j.1471-4159.2005.03135.x

Perry, G., Friedman, R., Shaw, G., and Chau, V. (1987). Ubiquitin is detected in neurofibrillary tangles and senile plaque neurites of Alzheimer disease brains. Proc. Natl. Acad. Sci. U.S.A. 84, 3033-3036. doi: 10.1073/pnas.84.9.3033

Petrucelli, L., Dickson, D., Kehoe, K., Taylor, J., Snyder, H., Grover, A., et al. (2004) CHIP and Hsp70 regulate tau ubiquitination, degradation and aggregation. Hum. Mol. Genet. 13, 703-714. doi: 10.1093/hmg/ddh083

Petrucelli, L., O’Farrell, C., Lockhart, P. J., Baptista, M., Kehoe, K., Vink, L., et al. (2002). Parkin protects against the toxicity associated with mutant alpha-synuclein: proteasome dysfunction selectively affects catecholaminergic neurons. Neuron 36, 1007-1019. doi: 10.1016/S0896-6273(02)01125-X

Pielot, R., Smalla, K. H., Muller, A., Landgraf, P., Lehmann, A. C., Eisenschmidt, E., et al. (2012). SynProt: a database for proteins of detergentresistant synaptic protein preparations. Front. Synaptic Neurosci. 4:1. doi: 10.3389/fnsyn.2012.00001

Pines, J. (2006). Mitosis: a matter of getting rid of the right protein at the right time. Trends Cell Biol. 16, 55-63. doi: 10.1016/j.tcb.2005.11.006

Polymenidou, M., Lagier-Tourenne, C., Hutt, K. R., Huelga, S. C., Moran, J., Liang, T. Y., et al. (2011). Long pre-mRNA depletion and RNA missplicing contribute to neuronal vulnerability from loss of TDP-43. Nat. Neurosci. 14, 459-468. doi: 10.1038/nn.2779

Poon, W. W., Carlos, A. J., Aguilar, B. L., Berchtold, N. C., Kawano, C. K., Zograbyan, V., et al. (2013). beta-Amyloid (Abeta) oligomers impair brainderived neurotrophic factor retrograde trafficking by down-regulating ubiquitin C-terminal hydrolase, UCH-L1. J. Biol. Chem. 288, 16937-16948. doi: 10.1074/jbc.M113.463711 
Proctor, C. J., and Gray, D. A. (2010). GSK3 and p53 - is there a link in Alzheimer's disease? Mol. Neurodegener. 5, 7. doi: 10.1186/1750-1326-5-7

Quy, P. N., Kuma, A., Pierre, P., and Mizushima, N. (2013). Proteasome-dependent activation of mammalian target of rapamycin complex 1 (mTORC1) is essential for autophagy suppression and muscle remodeling following denervation. J. Biol. Chem. 288, 1125-1134. doi: 10.1074/jbc.M112.399949

Ramon y Cajal, S. (1909). Histologie du Systeme Nerveux de L'homme \& des Vertebres, Vol. 2. Paris: A. Maloine.

Raspe, M., Gillis, J., Krol, H., Krom, S., Bosch, K., van Veen, H., et al. (2009). Mimicking proteasomal release of polyglutamine peptides initiates aggregation and toxicity. J. Cell Sci. 122(Pt 18), 3262-3271. doi: 10.1242/jcs.045567

Richet, E., Pooler, A. M., Rodriguez, T., Novoselov, S. S., Schmidtke, G., Groettrup, M., et al. (2012). NUB1 modulation of GSK3beta reduces tau aggregation. Hum. Mol. Genet. 21, 5254-5267. doi: 10.1093/hmg/dds376

Riess, O., Jakes, R., and Kruger, R. (1998). Genetic dissection of familial Parkinson's disease. Mol. Med. Today 4, 438-444. doi: 10.1016/S1357-4310(98)01343-4

Robertson, A. L., Bate, M. A., Androulakis, S. G., Bottomley, S. P., and Buckle, A. M. (2011). PolyQ: a database describing the sequence and domain context of polyglutamine repeats in proteins. Nucleic Acids Res. 39, D272-D276. doi: 10.1093/nar/gkq1100

Rosen, D. R., Siddique, T., Patterson, D., Figlewicz, D. A., Sapp, P., Hentati, A., et al. (1993). Mutations in $\mathrm{Cu} / \mathrm{Zn}$ superoxide dismutase gene are associated with familial amyotrophic lateral sclerosis. Nature 362, 59-62. doi: 10.1038/362059a0

Ross, C. A. (1995). When more is less: pathogenesis of glutamine repeat neurodegenerative diseases. Neuron 15, 493-496. doi: 10.1016/0896-6273(95)90138-8

Ross, C. A., and Poirier, M. A. (2005). Opinion: what is the role of protein aggregation in neurodegeneration? Nat. Rev. Mol. Cell Biol. 6, 891-898. doi: $10.1038 / \mathrm{nrm} 1742$

Sabatini, D. M., Erdjument-Bromage, H., Lui, M., Tempst, P., and Snyder, S. H. (1994). RAFT1: a mammalian protein that binds to FKBP12 in a rapamycindependent fashion and is homologous to yeast TORs. Cell 78, 35-43. doi: 10.1016/0092-8674(94)90570-3

Scaglione, K. M., Basrur, V., Ashraf, N. S., Konen, J. R., Elenitoba-Johnson, K. S., Todi, S. V., et al. (2013). The ubiquitin-conjugating enzyme (E2) Ube2w ubiquitinates the $\mathrm{N}$ terminus of substrates. J. Biol. Chem. 288, 18784-18788. doi: 10.1074/jbc.C113.477596

Scaglione, K. M., Zavodszky, E., Todi, S. V., Patury, S., Xu, P., Rodriguez-Lebron, E., et al. (2011). Ube $2 \mathrm{w}$ and ataxin-3 coordinately regulate the ubiquitin ligase CHIP. Mol. Cell 43, 599-612. doi: 10.1016/j.molcel.2011.05.036

Schnell, J. D., and Hicke, L. (2003). Non-traditional functions of ubiquitin and ubiquitin-binding proteins. J. Biol. Chem. 278, 35857-35860. doi: 10.1074/jbc.R300018200

Seo, H., Sonntag, K. C., and Isacson, O. (2004). Generalized brain and skin proteasome inhibition in Huntington's disease. Ann. Neurol. 56, 319-328. doi: 10.1002/ana.20207

Seo, H., Sonntag, K. C., Kim, W., Cattaneo, E., and Isacson, O. (2007). Proteasome activator enhances survival of Huntington's disease neuronal model cells. PLoS ONE 2:e238. doi: 10.1371/journal.pone.0000238

Shang, F., and Taylor, A. (2011). Ubiquitin-proteasome pathway and cellular responses to oxidative stress. Free Radic. Biol. Med. 51, 5-16. doi: 10.1016/j.freeradbiomed.2011.03.031

Shankar, G. M., Bloodgood, B. L., Townsend, M., Walsh, D. M., Selkoe, D. J., and Sabatini, B. L. (2007). Natural oligomers of the Alzheimer amyloid-beta protein induce reversible synapse loss by modulating an NMDA-type glutamate receptor-dependent signaling pathway. J. Neurosci. 27, 2866-2875. doi: 10.1523/JNEUROSCI.4970-06.2007

Shimura, H., Hattori, N., Kubo, S., Mizuno, Y., Asakawa, S., Minoshima, S., et al. (2000). Familial Parkinson disease gene product, parkin, is a ubiquitin-protein ligase. Nat. Genet. 25, 302-305. doi: 10.1038/77060

Shimura, H., Schlossmacher, M. G., Hattori, N., Frosch, M. P., Trockenbacher, A., Schneider, R., et al. (2001). Ubiquitination of a new form of alpha-synuclein by parkin from human brain: implications for Parkinson's disease. Science 293, 263-269. doi: 10.1126/science.1060627

Shin, S. M., Zhang, N., Hansen, J., Gerges, N. Z., Pak, D. T., Sheng, M., et al. (2012). GKAP orchestrates activity-dependent postsynaptic protein remodeling and homeostatic scaling. Nat. Neurosci. 15, 1655-1666. doi: 10.1038/ nn.3259

Simon-Sanchez, J., Dopper, E. G., Cohn-Hokke, P. E., Hukema, R. K., Nicolaou, N., Seelaar, H., et al. (2012). The clinical and pathological phenotype of
C9ORF72 hexanucleotide repeat expansions. Brain 135(Pt 3), 723-735. doi: 10.1093/brain/awr353

Skaar, J. R., Pagan, J. K., and Pagano, M. (2009). SnapShot: F box proteins I. Cell 137, 1160-e1. doi: 10.1016/j.cell.2009.05.039

Snell, R. G., MacMillan, J. C., Cheadle, J. P., Fenton, I., Lazarou, L. P., Davies, P., et al. (1993). Relationship between trinucleotide repeat expansion and phenotypic variation in Huntington's disease. Nat. Genet. 4, 393-397. doi: 10.1038/ng0893-393

Sone, J., Niwa, J., Kawai, K., Ishigaki, S., Yamada, S., Adachi, H., et al. (2010). Dorfin ameliorates phenotypes in a transgenic mouse model of amyotrophic lateral sclerosis. J. Neurosci. Res. 88, 123-135. doi: 10.1002/jnr.22175

Steffan, J. S., Agrawal, N., Pallos, J., Rockabrand, E., Trotman, L. C., Slepko, N., et al. (2004). SUMO modification of Huntingtin and Huntington's disease pathology. Science 304, 100-104. doi: 10.1126/science.1092194

Stieren, E. S., El Ayadi, A., Xiao, Y., Siller, E., Landsverk, M. L., Oberhauser, A. F., et al. (2011). Ubiquilin-1 is a molecular chaperone for the amyloid precursor protein. J. Biol. Chem. 286, 35689-35698. doi: 10.1074/jbc.M111.243147

Subramaniam, S., Sixt, K. M., Barrow, R., and Snyder, S. H. (2009). Rhes, a striatal specific protein, mediates mutant-huntingtin cytotoxicity. Science 324, 1327-1330. doi: 10.1126/science.1172871

Suhr, S. T., Senut, M. C., Whitelegge, J. P., Faull, K. F., Cuizon, D. B., and Gage, F. H. (2001). Identities of sequestered proteins in aggregates from cells with induced polyglutamine expression. J. Cell Biol. 153, 283-294. doi: 10.1083/jcb. 153.2.283

Suzuki, Y., Nakabayashi, Y., and Takahashi, R. (2001). Ubiquitin-protein ligase activity of $\mathrm{X}$-linked inhibitor of apoptosis protein promotes proteasomal degradation of caspase-3 and enhances its anti-apoptotic effect in Fas-induced cell death. Proc. Natl. Acad. Sci. U.S.A. 98, 8662-8667. doi: 10.1073/pnas. 161506698

Syme, C. D., Blanch, E. W., Holt, C., Jakes, R., Goedert, M., Hecht, L., et al. (2002). A Raman optical activity study of rheomorphism in caseins, synucleins and tau. New insight into the structure and behaviour of natively unfolded proteins. Eur. J. Biochem. 269, 148-156. doi: 10.1046/j.0014-2956.2001. 02633.x

Talantova, M., Sanz-Blasco, S., Zhang, X., Xia, P., Akhtar, M. W., Okamoto, S., et al. (2013). Abeta induces astrocytic glutamate release, extrasynaptic NMDA receptor activation, and synaptic loss. Proc. Natl. Acad. Sci. U.S.A. 110, E2518-E2527. doi: $10.1073 /$ pnas. 1306832110

Thinakaran, G., and Koo, E. H. (2008). Amyloid precursor protein trafficking, processing, and function. J. Biol. Chem. 283, 29615-29619. doi: 10.1074/jbc.R800019200

Valente, E. M., Abou-Sleiman, P. M., Caputo, V., Muqit, M. M., Harvey, K., Gispert, S., et al. (2004). Hereditary early-onset Parkinson's disease caused by mutations in PINK1. Science 304, 1158-1160. doi: 10.1126/science.1096284

van Bergen En Henegouwen, P. M. (2009). Eps15: a multifunctional adaptor protein regulating intracellular trafficking. Cell Commun. Signal. 7, 24. doi: 10.1186/1478-811X-7-24

van Blitterswijk, M., DeJesus-Hernandez, M., and Rademakers, R. (2012). How do C9ORF72 repeat expansions cause amyotrophic lateral sclerosis and frontotemporal dementia: can we learn from other noncoding repeat expansion disorders? Curr. Opin. Neurol. 25, 689-700. doi: 10.1097/WCO.0b013e32835a3efb

Venkatraman, P., Wetzel, R., Tanaka, M., Nukina, N., and Goldberg, A. L. (2004). Eukaryotic proteasomes cannot digest polyglutamine sequences and release them during degradation of polyglutamine-containing proteins. Mol. Cell 14, 95-104. doi: 10.1016/S1097-2765(04)00151-0

Vincow, E. S., Merrihew, G., Thomas, R. E., Shulman, N. J., Beyer, R. P., MacCoss, M. J., et al. (2013). The PINK1-Parkin pathway promotes both mitophagy and selective respiratory chain turnover in vivo. Proc. Natl. Acad. Sci. U.S.A. 110, 6400-6405. doi: 10.1073/pnas. 1221132110

Walker, F. O. (2007). Huntington's disease. Lancet 369, 218-228. doi: 10.1016/S0140-6736(07)60111-1

Walling, A. D. (1999). Amyotrophic lateral sclerosis: Lou Gehrig's disease. Am. Fam. Physician 59, 1489-1496.

Wilkinson, K. D. (1997). Regulation of ubiquitin-dependent processes by deubiquitinating enzymes. FASEB J. 11, 1245-1256.

Wilkinson, K. D. (2009). DUBs at a glance. J. Cell Sci. 122(Pt 14), 2325-2329. doi: $10.1242 /$ jcs. 041046

Williams, A. J., Knutson, T. M., Colomer Gould, V. F., and Paulson, H. L. (2009). In vivo suppression of polyglutamine neurotoxicity by C-terminus of 
Hsp70-interacting protein (CHIP) supports an aggregation model of pathogenesis. Neurobiol. Dis. 33, 342-353. doi: 10.1016/j.nbd.2008.10.016

Wischik, C. M., Novak, M., Thogersen, H. C., Edwards, P. C., Runswick, M. J., Jakes, R., et al. (1988). Isolation of a fragment of tau derived from the core of the paired helical filament of Alzheimer disease. Proc. Natl. Acad. Sci. U.S.A. 85, 4506-4510. doi: 10.1073/pnas.85.12.4506

Xia, Z. P., Sun, L., Chen, X., Pineda, G., Jiang, X., Adhikari, A., et al. (2009). Direct activation of protein kinases by unanchored polyubiquitin chains. Nature 461, 114-119. doi: 10.1038/nature08247

Xiong, H., Wang, D., Chen, L., Choo, Y. S., Ma, H., Tang, C., et al. (2009). Parkin, PINK1, and DJ-1 form a ubiquitin E3 ligase complex promoting unfolded protein degradation. J. Clin. Invest. 119, 650-660. doi: 10.1172/JCI37617

Xu, P., Duong, D. M., Seyfried, N. T., Cheng, D., Xie, Y., Robert, J., et al. (2009). Quantitative proteomics reveals the function of unconventional ubiquitin chains in proteasomal degradation. Cell 137, 133-145. doi: 10.1016/j.cell. 2009.01.041

Yang, H., Zhong, X., Ballar, P., Luo, S., Shen, Y., Rubinsztein, D. C., et al. (2007). Ubiquitin ligase Hrdl enhances the degradation and suppresses the toxicity of polyglutamine-expanded Huntingtin. Exp. Cell Res. 313, 538-550. doi: 10.1016/ j.yexcr.2006.10.031

Yoshida, Y., Chiba, T., Tokunaga, F., Kawasaki, H., Iwai, K., Suzuki, T., et al. (2002). E3 ubiquitin ligase that recognizes sugar chains. Nature 418, 438-442. doi: 10.1038/nature00890

Yoshii, S. R., Kishi, C., Ishihara, N., and Mizushima, N. (2011). Parkin mediates proteasome-dependent protein degradation and rupture of the outer mitochondrial membrane. J. Biol. Chem. 286, 19630-19640. doi: 10.1074/jbc.M110. 209338

Zhang, F., Hu, M., Tian, G., Zhang, P., Finley, D., Jeffrey, P. D., et al. (2009). Structural insights into the regulatory particle of the proteasome from
Methanocaldococcus jannaschii. Mol. Cell 34, 473-484. doi: 10.1016/j.molcel. 2009.04.021

Zhang, L., Xu, M., Scotti, E., Chen, Z. J., and Tontonoz, P. (2013). Both K63 and K48 ubiquitin linkages signal lysosomal degradation of the LDL receptor. J. Lipid Res. 54, 1410-1420. doi: 10.1194/jlr.M035774

Ziv, I., Matiuhin, Y., Kirkpatrick, D. S., Erpapazoglou, Z., Leon, S., Pantazopoulou, M., et al. (2011). A perturbed ubiquitin landscape distinguishes between ubiquitin in trafficking and in proteolysis. Mol. Cell. Proteomics 10, M111.009753. doi: 10.1074/mcp.M111.009753

Zucchelli, S., Marcuzzi, F., Codrich, M., Agostoni, E., Vilotti, S., Biagioli, M., et al. (2011). Tumor necrosis factor receptor-associated factor 6 (TRAF6) associates with Huntingtin protein and promotes its atypical ubiquitination to enhance aggregate formation. J. Biol. Chem. 286, 25108-25117. doi: 10.1074/jbc.M110.187591

Conflict of Interest Statement: The authors declare that the research was conducted in the absence of any commercial or financial relationships that could be construed as a potential conflict of interest.

Received: 29 April 2014; accepted: 19 June 2014; published online: 08 July 2014

Citation: Atkin $G$ and Paulson $H$ (2014) Ubiquitin pathways in neurodegenerative disease. Front. Mol. Neurosci. 7:63. doi: 10.3389/fnmol.2014.00063

This article was submitted to the journal Frontiers in Molecular Neuroscience.

Copyright (c) 2014 Atkin and Paulson. This is an open-access article distributed under the terms of the Creative Commons Attribution License (CC BY). The use, distribution or reproduction in other forums is permitted, provided the original author(s) or licensor are credited and that the original publication in this journal is cited, in accordance with accepted academic practice. No use, distribution or reproduction is permitted which does not comply with these terms. 